\title{
Molecular basis of signaling specificity of insulin and IGF receptors: neglected corners and recent advances
}

\section{Kenneth Siddle*}

University of Cambridge Metabolic Research Laboratories and Department of Clinical Biochemistry, Institute of Metabolic Science, Addenbrooke's Hospital, Cambridge, UK

\section{Edited by:}

Michael Lawrence, The Walter and Eliza Hall Institute of Medical

Research, Australia

\section{Reviewed by:}

Rosemary O'Connor, University

College Cork, Ireland

Stevan Hubbard, New York University

School of Medicine, USA

\section{${ }^{*}$ Correspondence:}

Kenneth Siddle, University of Cambridge Metabolic Research Laboratories, Institute of Metabolic Science, Addenbrooke's Hospital, Cambridge CB2 0QQ, UK. e-mail:ks14@mole.bio.cam.ac.uk
Insulin and insulin-like growth factor (IGF) receptors utilize common phosphoinositide 3kinase/Akt and Ras/extracellular signal-regulated kinase signaling pathways to mediate a broad spectrum of "metabolic" and "mitogenic" responses. Specificity of insulin and IGF action in vivo must in part reflect expression of receptors and responsive pathways in different tissues but it is widely assumed that it is also determined by the ligand binding and signaling mechanisms of the receptors. This review focuses on receptor-proximal events in insulin/IGF signaling and examines their contribution to specificity of downstream responses. Insulin and IGF receptors may differ subtly in the efficiency with which they recruit their major substrates (IRS-1 and IRS-2 and Shc) and this could influence effectiveness of signaling to "metabolic" and "mitogenic" responses. Other substrates (Grb2associated binder, downstream of kinases, SH2Bs, Crk), scaffolds (RACK1, $\beta$-arrestins, cytohesins), and pathways (non-receptor tyrosine kinases, phosphoinositide kinases, reactive oxygen species) have been less widely studied. Some of these components appear to be specifically involved in "metabolic" or "mitogenic" signaling but it has not been shown that this reflects receptor-preferential interaction. Very few receptor-specific interactions have been characterized, and their roles in signaling are unclear. Signaling specificity might also be imparted by differences in intracellular trafficking or feedback regulation of receptors, but few studies have directly addressed this possibility. Although published data are not wholly conclusive, no evidence has yet emerged for signaling mechanisms that are specifically engaged by insulin receptors but not IGF receptors or vice versa, and there is only limited evidence for differential activation of signaling mechanisms that are common to both receptors. Cellular context, rather than intrinsic receptor activity, therefore appears to be the major determinant of whether responses to insulin and IGFs are perceived as "metabolic" or "mitogenic."

Keywords: insulin receptor, IGF receptor, substrate, adaptor, scaffold, kinase, signaling, specificity

\section{INTRODUCTION}

Insulin and the insulin-like growth factors together control many aspects of metabolism and growth in a wide range of mammalian tissues and play distinct physiological roles in vivo (Nakae et al., 2001). Insulin is most conspicuously involved in regulating the metabolism of glucose and lipids in muscle, fat, and liver, ensuring the coordinated uptake and storage of the products of digestion. However, studies in receptor knockout mouse models reveal key additional roles of insulin in other tissues including brain, pancreatic $\beta$-cells, and vascular endothelium (Kitamura et al., 2003; Kulkarni, 2005; Plum et al., 2006). Insulin-like growth factors

Abbreviations: APS, adaptor with PH and SH2 domains; CAP, Cbl-associated protein; Cbl, Casitas B lineage lymphoma; DOK, downstream of kinase; ERK, extracellular signal-regulated kinase; Gab, Grb2-associated binder; IGF, insulinlike growth factor; IGFR, type 1 insulin-like growth factor receptor; IR, insulin receptor; IRS, insulin receptor substrate; MEK, MAPK/ERK kinase; PH, pleckstrin homology; PI3K, phosphoinositide 3-kinase; PTB, phosphotyrosine-binding; RTK, receptor tyrosine kinase; $\mathrm{SH} 2$, Src-homology-2.
(IGFs) promote both cell growth and differentiation, IGF-2 being most important at the fetal stage and IGF-1 more significant postnatally, at least in rodents. Again, knockout mouse models have been important in defining the role of the IGF receptor and its ligands in vivo (Butler and LeRoith, 2001). Additionally, signaling by both insulin and IGFs is implicated in the regulation of lifespan (Narasimhan et al., 2009) and in neoplasia (Pollak, 2008).

Two canonical signaling pathways, usually referred to as the phosphoinositide 3-kinase (PI3K)/Akt and Ras/extracellular signal-regulated kinase (ERK) pathways, are central in mediating actions of both the insulin receptor (IR) and type 1 insulin-like growth factor receptor (IGFR; Adams et al., 2004; Cohen, 2006; Taniguchi et al., 2006; Laviola et al., 2007; Figure 1). Both these pathways act via phosphorylation to regulate multiple targets, with diverse physiological roles. Identification of potential Akt substrates has arguably outstripped their validation as important physiological targets (Manning and Cantley, 2007) while an extensive mTOR-regulated phosphoproteome, itself dependent in part on activation of Akt, has only recently been revealed (Hsu et al., 


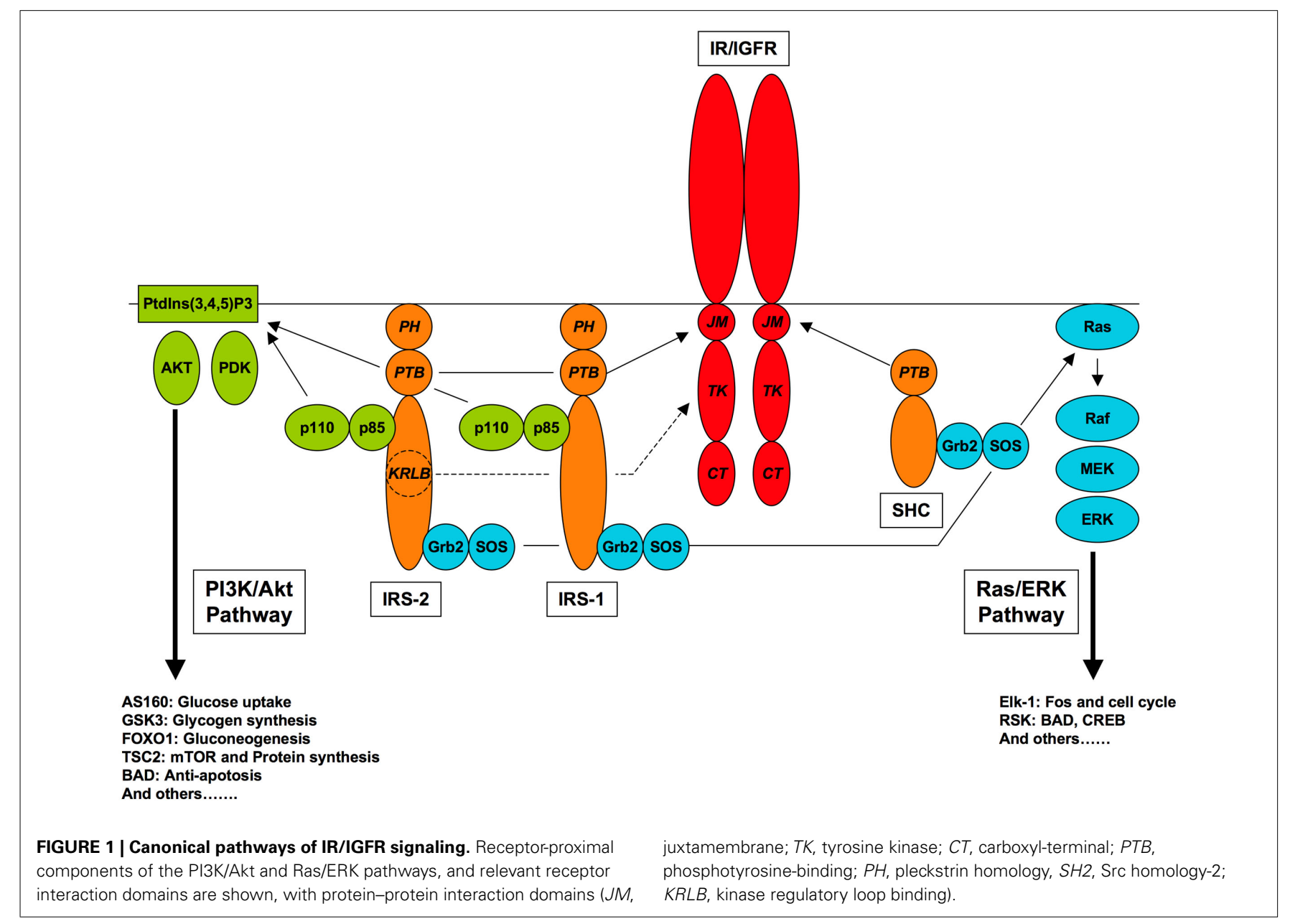

2011; Yu et al., 2011). ERK is also a promiscuous kinase that can phosphorylate more than 100 different substrates (Ramos, 2008). It is well established that the PI3K/Akt pathway mediates acute metabolic effects of insulin, and that it also regulates gene expression at the level of both transcription and translation, affecting growth and proliferation as well as metabolism. The Ras/ERK pathway has little or no acute metabolic role but mediates effects on proliferation and differentiation through regulation of gene transcription (Avruch, 2007; Meloche and Pouyssegur, 2007).

It is widely assumed that signaling specificity underlying the largely "metabolic" effects of insulin and "growth-promoting" effects of IGFs is conferred by features intrinsic to the ligands or receptors themselves (Dupont and LeRoith, 2001; Siddle et al., 2001; Kim and Accili, 2002). However, stimulus/response specificity in vivo must in part reflect the levels of expression of receptors and downstream targets in different tissues (Dumont et al., 2001, 2002) and it should therefore be unsurprising that differentiated tissues respond differently to insulin and IGFs. Moreover, it has repeatedly been shown that IR can mediate mitogenic responses and IGFR metabolic responses, both in vitro and in vivo (Dozio et al., 1995; Di Cola et al., 1997; Ish-Shalom et al., 1997; Louvi et al., 1997; Morrione et al., 1997; Baudry et al., 2001) and that, when studied in the same cell background, the activities of IR and IGFR are very similar (Weiland et al., 1991; Lund et al., 1994;
Wilson et al., 1995; Boucher et al., 2010b). Nevertheless differences in responses to insulin and IGFs have been reported in a variety of cell types (Miele et al., 2000; Dupont et al., 2001; Da Silva Xavier et al., 2004; Entingh-Pearsall and Kahn, 2004; Palsgaard et al., 2009), and the issue of whether and by what mechanisms the IR and IGFR exhibit intrinsic signaling specificity remains contentious. The issue is further complicated by the existence of heterodimeric insulin/IGF hybrid receptors alongside classical IR and IGFR homodimers (reviewed in Belfiore et al., 2009). Hybrid receptors bind insulin but not IGFs with high affinity (Soos et al., 1993), and their assembly appears to reflect the mole fractions of the individual receptors (Bailyes et al., 1997). Thus in cells expressing both IR and IGFR the less abundant receptor is found predominantly in hybrids rather than homodimers.

Specificity of insulin/IGF signaling might in principle be conferred by the kinetics and mechanism of ligand binding, affecting the duration and precise nature of receptor activation and the cellular itinerary of activated receptors (reviewed in Jensen and De Meyts, 2009). It was first shown in relation to NGF and EGF signaling that the kinetics of activation of the ERK pathway can determine distinct biological responses (Traverse et al., 1992, 1994; Tombes et al., 1998). There is little published information directly comparing the kinetics of activation of signaling pathways by IR and IGFR, let alone relating this to the kinetics of ligand binding. 
However, studies of different IR ligands indicate that binding kinetics can indeed differentially influence "metabolic" and "mitogenic" potencies. The hyper-mitogenic activity of some insulin analogs correlates with slow dissociation kinetics and persistent receptor occupancy, increased phosphorylation of Shc and activation of the Ras/ERK pathway (Hansen et al., 1996). Conversely, an insulin-mimetic peptide S597 that is not internalized has weak mitogenic activity relative to its metabolic potency (Jensen et al., 2008). It has been reported that IGF-2 is a more potent mitogen than insulin when acting on the IR-A isoform, correlating with more persistent ERK activation (Frasca et al., 1999; Sacco et al., 2009). In this case it seems unlikely that relative mitogenic potency of the two ligands is related to persistence of receptor occupancy as IR-A binds IGF-2 with lower affinity than insulin. It has also been reported that IR-A isoform is more "mitogenic" than the B isoform (Belfiore et al., 2009; Giudice et al., 2011). As the isoforms are identical in their intracellular domains, differences in activity can only be due to the small difference in structure of the extracellular domains (absence or presence of the sequence encoded by IR exon 11, at the extreme C-terminus of the $\alpha$-subunit). Insulin dissociates slightly faster from IR-A than from IR-B, at least at neutral pH (Yamaguchi et al., 1993), and it is therefore unlikely that differences in the persistence of occupancy could account for differential mitogenic signaling by the receptor isoforms. However IR-A apparently internalizes more rapidly than IR-B (Vogt et al., 1991; Yamaguchi et al., 1991; Giudice et al., 2011) and this could lead to more effective phosphorylation of Shc. Alternatively, differences in biological responses mediated by IR-A and IR-B in pancreatic $\beta$-cells have been attributed to localization of isoforms in separate lipid raft microdomains within which distinct signaling complexes may be assembled (Uhles et al., 2003; Leibiger et al., 2010b). However, there is no evidence for differential localization of IR isoforms expressed in HeLa cells (Giudice et al., 2011), and the capacity of both IR-A and IR-B to form hybrids with IGFR, as well as with each other, argues against substantial segregation of localization in most cell types. It should be noted that IGFR lacks the equivalent of IR exon 11.

In relation to the wider family of receptor tyrosine kinases (RTKs), signaling specificity is most obviously imparted by structural differences in the intracellular portions of the receptors, and differential interactions with proteins that initiate or modulate signaling pathways (Scott and Pawson, 2009; Lemmon and Schlessinger, 2010). The intracellular portions of IR and IGFR are highly similar in structure and amino acid sequence (Ullrich et al., $1985,1986)$ and the major sites of tyrosine autophosphorylation and the motifs that bind phosphotyrosine-binding (PTB) and $\mathrm{SH} 2$ domains of substrates and adaptors are highly conserved. Nevertheless, sequence differences, particularly in the carboxylterminal (CT) region, could well lead to differential interactions with signaling proteins that contribute to specificity of IR compared to IGFR. In support of this, differential signaling by the IR and IGFR intracellular domains fused to a common extracellular domain has been reported (Lammers et al., 1989; Urso et al., 1999; Mulligan et al., 2002). The remainder of this review will focus particularly on receptor-proximal events initiating welldocumented canonical signaling pathways together with some of the additional players whose role remains to be firmly established, highlighting aspects that may contribute to specificity of insulin and IGF action.

\section{RECEPTORS}

The mammalian IR and type 1 IGF receptor (IGFR) are closely related members of the class II RTK family (van der Geer et al., 1994). A third member of the family, the orphan IR-related receptor (IRR), has a very restricted tissue distribution and its function remains obscure. The distinctive feature of class II RTKs is that the proreceptor polypeptides are post-translationally processed by proteolytic cleavage and disulfide linkage to generate a functionally dimeric structure that is fundamental to the mechanisms of both ligand binding, involving cross-linking of $\alpha$-subunits, and tyrosine kinase (TK) activation, involving intra-molecular trans-phosphorylation of $\beta$-subunits (De Meyts, 2008).

\section{EXTRACELLULAR DOMAINS}

The structures of the whole extracellular portion of the IR and a fragment of the IGFR have been determined, revealing close similarity overall but differences in detail that may contribute to specificity of ligand binding (Lawrence et al., 2007). Attempts to co-crystallize ligand-receptor complexes have so far proved unsuccessful, but the mode of ligand binding, involving contacts in trans with both half-receptors, has been deduced from other lines of evidence (De Meyts and Whittaker, 2002; De Meyts, 2008). Despite the dimeric structure of the receptors, only a single molecule of ligand can make all the contacts required to bind with high affinity, and ligand binding demonstrates negative cooperativity fitting a harmonic oscillator model (Kiselyov et al., 2009). Interactions of insulin with IR have been studied in greatest detail, but the mode of binding of IGFs to IGFR appears to be very similar (Alvino et al., 2009). One difference of detail is that interaction of IGF-1 (but not IGF-2) with IGFR involves an additional binding epitope in the IGFR cysteine-rich domain (contacting IGF-1 C domain) that has no counterpart in insulin-IR interaction (Sorensen et al., 2004; Keyhanfar et al., 2007). It is not known what conformational changes are induced by ligand binding to trigger activation of the intracellular tyrosine kinase.

\section{INTRACELLULAR DOMAINS}

The intracellular TK domain of $\sim 250$ amino acids is flanked by a short juxtamembrane (JM) domain of $\sim 45$ amino acids and a longer CT domain of $\sim 100$ amino acids. Structures have been determined for the TK domains of IR and IGFR in basal and activated states, revealing that trans autophosphorylation of three conserved tyrosine residues within the regulatory loop of the TK domain (IR 1158/62/63, IGFR 1131/35/36) causes substantial conformational change, allowing access of intracellular substrates to the active site (Hubbard, 1997; Favelyukis et al., 2001) while also creating binding sites for regulatory adaptors of the Grb10/14 and APS/SH2-B families (Hu et al., 2003; Depetris et al., 2005; Hu and Hubbard, 2006). The primary sequences of IR and IGFR TK domains are $84 \%$ identical, and the tertiary structures are highly homologous, providing few insights into mechanisms that might confer signaling specificity. In particular the activation loop and nucleotide binding cleft are highly conserved, although there are limited sequence differences in the nearby interlobe linker which 
might allow a degree of specificity in interactions with protein substrates as well as giving encouragement to efforts to design selective inhibitors (Favelyukis et al., 2001). Apart from the conserved cluster of tyrosines in the activation loop, there are several other tyrosines within the TK domain of which four are conserved (IR 1011, 1087, 1122, 1210) while others are unique (IR 1227, IGFR 1162 and 1221). These residues are not known to be phosphorylated, and no specific function has been ascribed to them.

The short JM domains of $\sim 50$ amino acids are $\sim 65 \%$ identical between IR and IGFR, and include a conserved NPEY motif that is important for substrate recruitment. Autophosphorylation of this motif (IR Y972, IGFR Y950) creates a binding site for the PTB domains of insulin receptor substrates (IRSs) and Shc. The binding specificities and mechanisms of IRS and Shc PTB domains differ in detail and, as discussed below, the JM sequences of IR/IGFR appear optimal for binding IRS-1 but sub-optimal for binding Shc. Surprisingly, at least in terms of binding of short phosphopeptides by the respective recombinant PTB domains, Shc has a higher affinity than IRS-1 (Wolf et al., 1995; Farooq et al., 1999). However, the pleckstrin homology $(\mathrm{PH})$ domain of IRSs also plays a key role in membrane recruitment and contributes to the effectiveness of these proteins as IR/IGFR substrates (Voliovitch et al., 1995; Yenush et al., 1996), and in vivo IRSs may be recruited more effectively than Shc. Apart from the NPEpY $\beta$-turn motif itself, the residues identified as most important for binding IRS-1 (Leu at -8 ; Eck et al., 1996) and Shc (Asn at -3 , hydrophobic at -7 and -8 ; Trub et al., 1995) are fully conserved between IR and IGFR. However, there are non-conserved residues at $-9,-4$, and +1 relative to the phosphotyrosine, so it is possible that IR and IGFR may differ subtly in the efficiency with which they recruit their substrates. Differential engagement of IRSs and Shc by IR and IGFR could potentially affect the duration or subcellular targeting of signals.

The JM NPEY motif is also important for IR internalization, although its phosphorylation does not appear to be necessary for this process. An adjacent GPLY965 motif that contributes independently and additively with NPEY972 to insulin-stimulated IR endocytosis (Backer et al., 1992) is not conserved in IGFR (GVLY943). Two dileucine-like motifs that have been implicated in anchoring, endocytosis, and intracellular targeting of IR (LL998/9 and II1018/9) are also not conserved in IGFR (MS971/2 and VV991/2; Haft et al., 1998; Shackleton et al., 2002). Thus there is a potential structural basis for differences in the endocytosis and intracellular itineraries of IR and IGFR, although the molecular mechanisms of IR/IGFR endocytosis and trafficking remain poorly understood.

The IR and IGFR CT domains of $\sim 100$ amino acids are even more divergent in sequence and only $\sim 48 \%$ identical. It has been proposed that the phosphorylatable tyrosines IR1328 and IR1334 play a role in delineating "metabolic" versus "mitogenic" signaling, although in some cells IR appears to function normally without this portion of the CT domain (reviewed in Tavare and Siddle, 1993). It is notable however that IR1328 is not conserved in IGFR (IGFR F1310), while IGFR possesses twin tyrosines $(1250 / 51)$ that are not conserved in IR (IR FH1277/8). These IGFR twin tyrosines have not been shown to be phosphorylated upon receptor activation, but have been implicated in IGFR function by mutational analysis (Miura et al., 1995; Blakesley et al., 1996, 1998; Esposito et al., 1997; Miura and Baserga, 1997; Leahy et al., 2004; Kiely et al., 2005). Other distinctive features of the CT domains are a 12-residue serine-rich insertion in IGFR (including the cluster S1280/1/2/3) with no counterpart in IR and the terminal sequences (RSNPS in IR, QSSTC in IGFR). There is thus clear potential for differential binding of adaptor or regulatory proteins (particularly those with $\mathrm{SH} 2$ or PDZ domains) that might contribute to differential signaling by IR and IGFR.

\section{SUBSTRATES OF THE RECEPTOR TYROSINE KINASES}

Insulin receptor substrates and Shc proteins are recognized as the major substrates of the IR and IGFR TKs, through their roles in the canonical PI3K/Akt and Ras/ERK signaling pathways (Taniguchi et al., 2006). However, several other substrates have been characterized. Some of these, such as Grb2-associated binder (Gabs) and downstream of kinases (DOKs), seem to act as tissue- or pathway-specific alternatives to IRSs. Others, such as members of the $\mathrm{SH} 2 \mathrm{~B}$ and $\mathrm{Cbl}$ families, engage distinct signaling pathways and may also have roles in receptor regulation. Phosphoproteomic analysis of insulin-stimulated cells has revealed further tyrosinephosphorylated proteins, including potential signal transducers, but the significance of these substrates and the role of tyrosine phosphorylation in their regulation remains to be determined (Schmelzle et al., 2006; Kruger et al., 2008). No comparable analysis of IGF-responsive substrates has been published.

Although there is overwhelming evidence supporting the essential role of RTK activity in almost all insulin/IGF actions, kinaseindependent signaling by both IR and IGFR has been reported (Povsic et al., 2003; Zhang and Riedel, 2009). Most recently it has been shown that the unliganded IR and IGFR have a permissive effect on apoptosis that appears to be independent of PI3K/Akt and Ras/ERK signaling, in contrast to anti-apoptotic signaling by the ligand-activated receptors (Boucher et al., 2010a). The mechanism of kinase-independent signaling to apoptosis is unclear but it is apparently shared by both IR and IGFR.

\section{INSULIN RECEPTOR SUBSTRATES}

Insulin receptor substrates are relatively specific substrates of IR/IGFR TKs, reflecting their recruitment by dual interaction of PTB and PH domains with the receptor JM domain and membrane phospholipids and respectively (Wolf et al., 1995; White, 2002). IRS-1 and IRS-2 are widely expressed in mammalian tissues while IRS-3 and IRS-4 are more restricted in distribution. IRS- 1 and IRS- 2 each contain up to 20 potential tyrosine phosphorylation sites, although not all of these have been formally shown to be phosphorylated following insulin/IGF stimulation. For both these IRSs the importance of specific phosphotyrosinecontaining motifs in binding the $\mathrm{SH} 2$ domains of $\mathrm{PI} 3 \mathrm{~K}$ regulatory subunits and Grb2 is well established, and motifs binding the tyrosine-specific phosphatase SHP2 and the TK Fyn have also been identified (White, 2002). In the case of PI3K and SHP2, binding affinity and enzyme activation are enhanced by the simultaneous interaction of two SH2 domains with bisphosphorylated motifs (Hof et al., 1998; Ottinger et al., 1998). The role of SHP2 is particularly complex and poorly understood. It has been implicated 
in IRS-1 dephosphorylation (Myers et al., 1998) though this may be site-specific as in vascular smooth muscle cells SHP2 selectively antagonized IRS/Grb2/Sos signaling to ERK (Hayashi et al., 2004). However there is evidence that in some circumstances SHP2 can act as a positive effector for insulin signaling via Ras/ERK (Xiao et al., 1994; Yamauchi et al., 1995; Fukunaga et al., 2000) and for IGF-1 signaling via PI3K/Akt (Wu et al., 2001; Kwon et al., 2006), and that it is required for developmental, migratory, and proliferative responses (Saxton et al., 2000; Kwon et al., 2006; Forbes et al., 2009). The substrates and mechanisms underlying such paradoxical potentiation of insulin/IGF signaling by SHP2 are unknown. Moreover SHP2 also binds to autophosphorylated IR and IGFR (Rocchi et al., 1996) and to the scaffold protein SHPS-1 (Maile and Clemmons, 2002), and it is unclear how its different interactions contribute to its biological effects.

Application of proteomic techniques has further extended the spectrum of potential IRS interaction partners, although without reference to which sites actually become phosphorylated following insulin/IGF stimulation of intact cells (Hanke and Mann, 2009). The partial functional redundancy of IRS- 1 and IRS-2 was confirmed by identification of a large number of common interactors, although several proteins involved in signaling and metabolism were found to interact differentially with sites in IRS-1 and IRS2, providing potential leads into their specific physiological roles. The data also suggested that modules other than SH2 and PTB domains may mediate binding to IRS phosphotyrosines.

IRS-1 and IRS-2 exhibit distinct patterns of subcellular compartmentalization and trafficking (Inoue et al., 1998; Clark et al., 2000). The molecular interactions that determine subcellular localization of IRSs before or after their tyrosine phosphorylation are unclear, but may involve binding of the respective $\mathrm{PH}$ domains to specific phosphoinositides (Razzini et al., 2000). Whatever the mechanism, localization of IRSs clearly has the potential to influence both their tyrosine phosphorylation and engagement with signaling proteins.

Although at a cellular level IRS- 1 and IRS- 2 mediate very similar signaling pathways that are implicated in both metabolic and growth responses, their physiological roles appear to be distinct. At the organismal level this functional specificity presumably reflects differences in tissue distribution as well as molecular interactions. The phenotypes of mice with specific gene deletions indicate that IRS-1 is more important than IRS-2 in regulating organismal growth while IRS-2 is more important in glucose homeostasis. However, this "metabolic" function of IRS-2 in part reflects a role in mediating growth-promoting effects of IGF-1 in pancreatic beta cells (White, 2002). At a cellular level, in liver and skeletal muscle IRS-1 appears to be most closely linked to insulin's regulation of glucose homeostasis and IRS-2 to regulation of lipid metabolism and/or ERK activation (Huang et al., 2005; Taniguchi et al., 2005; Bouzakri et al., 2006; Thirone et al., 2006), although the mechanisms underlying this specificity are not well understood.

As discussed above, the JM sequences of IR and IGFR are well conserved but not identical, leaving open the possibility that they might bind the PTB domains of IRSs with slightly different affinity and thus phosphorylate them with slightly different efficiency. IRS-2 additionally interacts with the TK domain of IR, though less well with IGFR, via a kinase regulatory loop binding (KRLB) region (Van Obberghen et al., 2001; Wu et al., 2008). Structural studies suggest this interaction limits rather than facilitates phosphorylation of IRS-2 by IR and the lack of this constraint with IGFR could contribute to differential phosphorylation by the two receptors (Wu et al., 2008). In principle, differences in the mechanism or efficiency of IRS recruitment could affect both the overall extent and the pattern of their phosphorylation by IR compared to IGFR. There is evidence that IRS-1 is phosphorylated more effectively by IR than by IGFR (Urso et al., 1999) and, conversely, that IRS-2 is phosphorylated more effectively by IGFR than by IR, consistent with the expected influence of the KRLB domain (Rakatzi et al., 2006). Further, it has been reported that IR-induced phosphorylation couples IRS-1 preferentially to PI3K while IGFRinduced phosphorylation couples preferentially to Grb2 (Amoui et al., 2001) and such differential effects might contribute to greater mitogenicity of IGFR compared to IR. Interestingly, induction of VEGF mRNA in NIH3T3 fibroblasts was reported to be mediated by a PI3K-dependent pathway for IR but a MAPK dependent pathway for IGFR (Miele et al., 2000). A recent microarray-based study concluded that IR and IGFR act as identical portals to the regulation of gene expression in brown adipocytes, and that quantitative differences between the effects of insulin and IGF-1 reflected the expression levels of the respective receptors (Boucher et al., 2010b). However, this study did not investigate the signaling pathways mediating gene expression changes, nor did it completely rule out the possibility that differences between IR and IGFR might exist in regulating genes with unusual kinetics or limited magnitude of expression changes.

\section{Shc PROTEINS}

Shc proteins are well-established alternative substrates of the IR and IGFR. The ubiquitous ShcA is expressed as three isoforms, $\mathrm{p} 66, \mathrm{p} 52$, and $\mathrm{p} 46$, which are products of alternative splicing and alternative translation initiation (Luzi et al., 2000). Whereas phosphorylation of p52/46 leads to activation of the Ras/ERK cascade, p66 is inhibitory to ERK activation by mechanisms that are unclear (Okada et al., 1997; Natalicchio et al., 2011). Moreover, the additional N-terminal collagen-homology domain of p66Shc confers unique properties leading to an isoform-specific role in the regulation of reactive oxygen species (ROS) levels and aging (Trinei et al., 2009). All three ShcA isoforms are tyrosine phosphorylated by multiple RTKs on two distinct sites (YY239/240 and Y317 in p52Shc). Although both sites are able to recruit the Grb2/Sos adaptor/GEF complex there is evidence that they are functionally distinct (Gotoh et al., 1997; Thomas and Bradshaw, 1997; Patrussi et al., 2005). At least in fibroblasts, it appears that $\mathrm{Y} 317$ of p52Shc is the more important site for activation of ERK by insulin (Sasaoka and Kobayashi, 2000).

The sequence flanking the JM NPXY motif of IR/IGFR is suboptimal for binding the PTB domain of Shc because it lacks a hydrophobic residue at -5 relative to phosphotyrosine (Trub et al., 1995) and in consequence, Shc is more efficiently phosphorylated by other RTKs. Furthermore phosphorylation of Shc (but not IRSs) is dependent on receptor internalization (Ceresa et al., 1998; Chow et al., 1998). Nevertheless, there is potential for competition between IRSs and Shc in binding via their PTB domains to the same site on IR (or IGFR), which could influence signaling 
to "metabolic" versus "mitogenic" responses (Sasaoka et al., 2001). It would be expected that "mitogenic" responses would be favored in cells expressing high levels of Shc compared to IRSs, regardless of whether stimulation is by insulin or IGFs. Moreover feedback or cross-talk mechanisms that inhibit association of IRSs with IR/IGFR (and thus inhibit "metabolic" signaling via the PI3K/Akt pathway, see below) might be expected to facilitate "mitogenic" signaling by Shc-dependent pathways.

Insulin receptor and IGFR generally induce only modest and transient activation of the Ras/ERK pathway, compared for instance to receptors that signal via the fibroblast growth factor receptor substrates (FRSs) which have multiple binding sites for Grb2 and SHP2 (Gotoh, 2008). Because both Shc and IRSs can recruit Grb2/Sos (Skolnik et al., 1993) the question arises as to which substrate plays the more important role in the mitogenic actions of IR and IGFR. In some cells it appears that Ras/ERK activation is mediated largely by Shc (Yamauchi and Pessin, 1994; Pruett et al., 1995; Kim et al., 1998; Boney et al., 2000; Sasaoka and Kobayashi, 2000) while in others IRS-dependent pathways appear to predominate (Takahashi et al., 1997; Liu et al., 2000). This divergence may reflect factors that are variable between cell types, including expression levels of IRS and Shc, and additional components. It is unclear whether IRS-bound and Shc-bound Grb2/Sos complexes would be equally effective activators of Ras, given potential differences in their subcellular localization and in the co-recruitment of additional signaling components. Ras is anchored in the plasma membrane by virtue of its prenylation, and its activation by Sos depends primarily on a proximity effect, although relief of a Sos autoinhibitory domain may also play a role (Aronheim et al., 1994; Boykevisch et al., 2006; Gureasko et al., 2008). Phosphorylation of IRSs but not Shc leads to recruitment of PI3K and SHP2 as well as Grb2. Interactions between PI3K and Ras reciprocally modulate both components (Shepherd et al., 1998), while SHP2 can apparently function as an additional adaptor facilitating Grb2/Sos recruitment (Dance et al., 2008).

\section{Gabs AND DOKs}

Grb2-associated binders lack a PTB domain but otherwise resemble IRSs in having an N-terminal PH domain and a C-terminal portion containing multiple potential sites of tyrosine phosphorylation (Nishida and Hirano, 2003). Unlike IRSs, Gabs have been implicated in signaling via many different receptors, with roles in growth and differentiation of multiple tissues and particularly in immune cell signaling (Nishida and Hirano, 2003; Sarmay et al., 2006). However, Gab-1 was first characterized as a substrate for IR and EGFR TKs (Holgado-Madruga et al., 1996). The major sites of insulin-stimulated Gab-1 phosphorylation have been identified, among which YXXM motifs with capacity to recruit and activate class Ia PI3K are prominent (Rocchi et al., 1998; Lehr et al., 2000). Gabs may play a role in insulin/IGF signaling in cells that do not express high levels of IRSs. For instance, signaling via Gab1 has been implicated in control of Egr-1 expression by insulin in fibroblasts (Harada et al., 2001). There is no published information comparing the capacity of IR and IGFR to phosphorylate Gabs.

Downstream of kinases have N-terminal PH and PTB domains similar to IRSs but with distinct specificity of interaction. Like
Gabs, DOKs are substrates for a variety of receptor and nonreceptor TKs, and they appear to be of particular importance in lymphocytes and myeloid cells (Mashima et al., 2009). DOKs are rapidly phosphorylated in response to stimulation by insulin and IGF-1, although this may be mediated in part by Src family kinases (Noguchi et al., 1999; Wick et al., 2001; Cai et al., 2003). DOK4 and DOK5 (also known as IRS-5 and IRS-6) are reportedly poor substrates for the IR (Versteyhe et al., 2010). Phosphorylated DOKs recruit a variety of $\mathrm{SH} 2$ domain-containing proteins but not including PI3K. DOK1 and DOK2 are negative regulators of the Ras/ERK pathway, probably dependent on their recruitment of RasGAP (Mashima et al., 2009). DOK4 also associates with RasGAP and with Crk, Src, and Fyn but lacks sites for PI3K, SHP2, or Grb2 recruitment. DOK5 does not associate with any of these proteins (Cai et al., 2003). Diverse roles have been proposed for DOK1 (p62dok) in insulin signaling (Noguchi et al., 1999; Wick et al., 2001; Hosooka et al., 2008), but it remains unclear whether this or other DOKs play a significant role in insulin/IGF actions in vivo.

\section{APS/SH2B AND CbL}

The APS/SH2-B (PSM) family of proteins are a group of IR substrates (Kotani et al., 1998; Ahmed et al., 1999; Moodie et al., 1999) that were originally characterized as components of TrkA signaling pathways and regulators of JAK family TKs (Qian and Ginty, 2001; O'Brien et al., 2002; Maures et al., 2007). These proteins have an $\mathrm{N}$-terminal proline-rich region and $\mathrm{PH}$ domain and C-terminal $\mathrm{SH} 2$ domain and tyrosine phosphorylation site. The proteins are recruited to the autophosphorylated IR by interaction of their $\mathrm{SH} 2$ domains with phosphotyrosines in the kinase regulatory loop, and it would expected (though this does not appear to have been formally demonstrated) that they would be similarly recruited by activated IGFR. Where both APS (SHB2) and SH2-B (SH2B1) are expressed it would be expected that they would compete for binding to IR/IGFR. Although the SH2 domains of APS and SH2B1 share $~ 80 \%$ sequence identity, $\mathrm{SH} 2 \mathrm{~B} 1$ preferentially binds JAK2 whereas APS has higher affinity for IR, this relative specificity being attributed to the fact that SH2B1 is predominantly monomeric while APS is dimeric (Hu et al., 2003; Hu and Hubbard, 2006). However, other studies suggested that $\mathrm{SH} 2 \mathrm{~B} 1$ can both homodimerize and heterodimerize with APS and that activation of JAK2 is promoted within $(\mathrm{SH} 2 \mathrm{~B})_{2}-(\mathrm{JAK} 2)_{2}$ heterotetramers, while kinase activation is blocked at higher relative concentrations of $\mathrm{SH} 2 \mathrm{~B}$ (Nishi et al., 2005).

APS acts as a scaffold, recruiting other proteins to the IR signaling complex, most notably c-Cbl, a multifunctional adaptor with ubiquitin ligase activity, that has been implicated in both signal transduction and degradation of various receptors in different cell types (Schmidt and Dikic, 2005; Thien and Langdon, 2005). $\mathrm{Cbl}$ is not a direct substrate of the IR but it binds via its $\mathrm{SH} 2$ domain to a phosphotyrosine motif in the C-terminal region of APS, facilitating its own tyrosine phosphorylation (Ahmed et al., 2000; Liu et al., 2002; Ahn et al., 2004; Hu and Hubbard, 2005). Cbl-associated protein (CAP) localizes the complex to lipid rafts by interaction with flotillin, while phospho-Cbl recruits the adaptor Crk which in turn recruits the guanine nucleotide exchange factor 
C3G, leading to activation of TC10, a member of the Rho family of small GTPases (Chang et al., 2004). Several effector mechanisms have been proposed to link TC10 to GLUT4 translocation, including actin remodeling (Kanzaki et al., 2002), targeting of atypical PKC (Kanzaki et al., 2004), assembly of exocyst complexes (Inoue et al., 2006), and generation of PtdIns3P (Falasca et al., 2007; Lodhi et al., 2008). It has been proposed that this constitutes a key accessory pathway, in addition to the PI3K/Akt pathway, in mediating insulin action on glucose transport. However, other data have called into question the importance of the CAP/Cbl pathway in the regulation of glucose transport. For instance the pathway does not appear to operate in skeletal muscle (JeBailey et al., 2004) and knockdown of key components of the pathway in adipocytes does not disrupt insulin-stimulated glucose transport (Zhou et al., 2004). Indeed, knockout of APS or c-Cbl in mice if anything improves peripheral insulin sensitivity (Minami et al., 2003; Molero et al., 2004; Li et al., 2006) and protects against dietinduced insulin resistance (Molero et al., 2006b). The effects of c-Cbl on insulin sensitivity revealed in mouse knockout models appear to be related to its ubiquitin ligase activity (Molero et al., 2006a) and it has been shown in cellular overexpression systems that APS-mediated recruitment of c-Cbl promotes ubiquitination of IR, enhancing its internalization without inducing degradation (Ahmed et al., 2000; Kishi et al., 2007). At the present time the precise role of the APS/CAP/Cbl pathway in IR function remains uncertain. Given its mode of interaction with IR, it would be anticipated that APS would also be an IGFR substrate although this has not been reported.

APS may additionally influence IR function by other mechanisms. Over-expression of APS has been reported to enhance IR autophosphorylation and ERK activation (Ahmed and Pillay, 2003; Onnockx et al., 2009). On the other hand, a splice variant of APS has been identified that lacks the SH2 domain and, by heterodimerization with either APS or SH2B2, is able to act as a negative regulator of insulin signaling (Li et al., 2007). Other APS binding partners have been reported, including Enigma, a PDZ and LIM domain-containing protein with potential involvement in insulin-induced actin cytoskeleton remodeling and GLUT4 translocation (Barres et al., 2005, 2006), Asb6, an adipocytespecific ankyrin and SOCS box protein that recruits elongins $\mathrm{B} / \mathrm{C}$ and potentially facilitates degradation (Wilcox et al., 2004) and the inositol polyphosphate $5^{\prime}$-phosphatase SHIP2 (Onnockx et al., 2008). APS is a substrate for phosphorylation by Akt (Katsanakis and Pillay, 2005), while expression of APS mRNA is down-regulated by a ERK-dependent pathway (Rea et al., 2005) suggesting that cross-talk from other insulin signaling pathways may regulate APS function.

SH2B1/PSM binds to many RTKs including both IR and IGFR, and to JAK associated with cytokine/leptin receptors (Riedel et al., 2000; Maures et al., 2007). Several isoforms of SH2B1 have been identified, differing in C-terminal sequence and possibly in biological activity (Maures et al., 2007; Zhang et al., 2008). Deletion of SH2B1 in mice results in severe obesity and both leptin and insulin resistance, supporting a role of $\mathrm{SH} 2 \mathrm{~B} 1$ as a positive regulator of JAK-mediated leptin signaling and possibly also of insulin signaling (Maures et al., 2007). In humans, genetic variation at the Sh2b1 locus has been associated with obesity (Thorleifsson et al.,
2009; Willer et al., 2009; Bochukova et al., 2010; Walters et al., 2010). Neuronal SH2B1 is primarily responsible for maintenance of energy balance, body weight, and glucose homeostasis (Ren et al., 2007; Morris et al., 2010a), although disruption of the SH2B1 gene in peripheral tissues impairs IR activation and signaling in liver, muscle, and fat and causes age-dependent glucose intolerance and insulin resistance (Duan et al., 2004; Morris et al., 2009). When overexpressed in cultured cells SH2B1, like APS, potentiates IR autophosphorylation, TK activity, and signaling (Zhang et al., 2008; Morris et al., 2009). Binding of SH2B1 stimulates IR catalytic activity in vitro and the $\mathrm{SH} 2$ domain is both necessary and sufficient to promote IR activation (Morris et al., 2009), although $\mathrm{N}$-terminal regions are additionally required for the maintenance of normal body weight and glucose metabolism (Morris et al., 2010a). Promotion of insulin signaling by SH2B1 may also in part reflect enhancement of IRS-1 phosphorylation by JAK2 (Li et al., 2007). It is unclear whether phosphorylation of SH2B1 and/or the recruitment of binding partners is necessary for its function in vivo. There have been few studies of the impact of SH2B1 on IGFR function, but there is no reason to suppose its actions would be specific to IR.

\section{Crk}

Yet another category of substrates is represented by the Crk family of adaptor proteins. Crk family adaptors are widely expressed and mediate formation of signaling complexes via their $\mathrm{SH} 2$ and SH3 domains in response to a variety of extracellular stimuli (Feller, 2001). CrkII was reported to interact with and be phosphorylated by both IGFR and IR, albeit with some differences in detail (Beitner-Johnson and LeRoith, 1995; Koval et al., 1998a; Klammt et al., 2004), but most functional studies have focused on a potential role in IGFR signaling. In NIH3T3 fibroblasts, overexpression of CrkII enhanced IGF-1-induced PI3K activation, actin filament reorganization and DNA synthesis but diminished ERK activation and cell cycle progression (Beitner-Johnson et al., 1996; Koval et al., 1998b; Goh et al., 2000). Crk has also been implicated in IGF-1 signaling pathways regulating early stages of adipocyte differentiation (Jin et al., 2000). The mechanisms underlying these effects are unclear, although as discussed above Crk has been invoked as a component of the $\mathrm{CAP} / \mathrm{Cbl}$ pathway, recruiting the guanine nucleotide exchange factor C3G (Chang et al., 2004). RNAi-mediated knockdown studies suggested CrkII is not required for insulin signaling to GLUT4 (Zhou et al., 2004), but this approach has not been applied to test involvement of Crk in other aspects of insulin/IGF action.

\section{NON-SUBSTRATE RECEPTOR ASSOCIATIONS: ADAPTORS AND SCAFFOLDS}

Various different classes of proteins have been identified that bind to the IR/IGFR but do not act as substrates for tyrosine phosphorylation. In some cases interactions with receptors are direct and have been characterized in considerable molecular detail while in others the mode of interaction with receptors remains obscure. These adaptor and scaffold proteins may modulate RTK activity or the interaction of the receptors with substrates, or may themselves recruit additional proteins that can function in downstream signaling. 


\section{Grb7/10/14}

The Grb7/10/14 adaptors were first identified as IR/IGFR binding partners in yeast two-hybrid studies. They are similar in overall structure to APS/SH2-B, having an N-terminal $\mathrm{PH}$ domain and C-terminal SH2 domain, but represent a distinct protein family. Grb7/10/14 exhibit overlapping but distinct patterns of tissue distribution and functional effects (reviewed in Holt and Siddle, 2005). They interact with multiple RTKs, but Grb10/14 have particular affinity for autophosphorylated IR/IGFR, binding via their $\mathrm{SH} 2$ domain to the autophosphorylation sites of the kinase regulatory loop and also via their BPS (between $\mathrm{PH}$ and $\mathrm{SH} 2$ ) domain as a pseudosubstrate inhibitor in the kinase active site (Stein et al., 2003; Depetris et al., 2005, 2009; Goenaga et al., 2009). When assayed in vitro, Grbs inhibit IR TK activity with potency order Grb14 > Grb10 > Grb7, and this inhibition is also exhibited by isolated BPS but not SH2 domains (Bereziat et al., 2002). There are indications that Grb14 exhibits greater potency for inhibiting IR compared to IGFR (Bereziat et al., 2002). Where Grbs and APS/SH2-B are co-expressed they would be expected to compete for binding to the IR/IGFR kinase regulatory loop, with potential then either to inhibit or activate TK activity depending on the dominant binding partner. Unlike APS/SH2-B, Grb10/14 are not substrates for the IR/IGFR TKs, although they are phosphorylated by other tyrosine and serine kinases (Langlais et al., 2000; Holt and Siddle, 2005; Sturk and Dumont, 2010). In particular, phosphorylation of Grb10 by mTORC1 potentiates its binding to IR/IGFR (and possibly to other receptors) and thus results in feedback inhibition of the PI3K and ERK pathways (Hsu et al., 2011; Yu et al., 2011).

A large body of evidence indicates that binding of Grb10/14 by IR/IGFR inhibits TK activity and IRS phosphorylation in intact cells (reviewed in Holt and Siddle, 2005). However, other studies suggest Grb10 has the potential to play a positive role in both metabolic and mitogenic signaling depending perhaps on expression levels and cellular context (Lim et al., 2004; Riedel, 2004). Binding of Grb10/14 prolongs receptor activation even while inhibiting phosphorylation of substrates, by site-specific protection of phosphotyrosines in the TK regulatory loop (Nouaille et al., 2006; Smith et al., 2007). Moreover both Grb10 and Grb14 recruit additional protein binding partners including Ras, PDK1, NEDD4, ZIP/PKC , and tankyrase (Holt and Siddle, 2005), some of which could contribute positively to signaling. Recruitment of PDK1 by Grb10 has been reported to facilitate Akt activation (King and Newton, 2004) but may also be required for maximum inhibition of insulin signaling (Goenaga et al., 2009). Grb14 may have additional actions downstream of IR to influence gene expression (Carre et al., 2008).

Gene deletion studies in mice confirm that Grb10 and Grb14 have overlapping but not identical actions, predominantly as inhibitors of insulin signaling, probably reflecting their different tissue distribution as well as their distinct binding partners (Holt et al., 2009). Grb10- and Grb14-deficient mice exhibit improved whole-body glucose homeostasis, reflecting enhanced insulin signaling (Cooney et al., 2004; Smith et al., 2007). However in both rodents and humans expression of Grb10 is imprinted in a tissue-specific manner (Blagitko et al., 2000) and this, together with its potential to interact with multiple RTKs, complicates interpretation of knockout phenotypes. Expression of Grb10 in peripheral tissues during embryogenesis is predominantly from the maternal allele, but within the brain Grb10 is paternally expressed. Ablation of the maternal allele results in fetal and placental overgrowth (Charalambous et al., 2003, 2010; Smith et al., 2007) while ablation of the paternal allele results in behavioral changes (Garfield et al., 2011). The contribution of altered regulation of IR/IGFR to these phenotypes is unclear, but the data are compatible with a modest inhibitory influence of endogenous Grb10 on both IR and IGFR function. Although Grb14 appears primarily to influence IR function, it is unclear whether this simply depends on co-expression or additionally reflects specificity of interaction

\section{RACK1 AND INTEGRINS}

Studies in several laboratories have implicated the scaffold protein RACK1 in interactions between IGFR and integrin signaling pathways that regulate cell adhesion and motility. Promotion of a metastatic and invasive phenotype is one of the mechanisms by which IGFR signaling contributes to cancer progression. RACK1 (receptor for activated C-kinases) is a WD repeat family member and homolog of $\mathrm{G}$ protein $\beta$-subunits (Ron et al., 1994; McCahill et al., 2002). It was identified as an IGFR-interacting protein in yeast two-hybrid screens (Hermanto et al., 2002; Kiely et al., 2002). Surprisingly, although the interaction of RACK1 with receptors is ligand-dependent, it does not require receptor TK activity or autophosphorylation (Kiely et al., 2002; Zhang et al., 2006). The interaction is mediated by the WD1-4 domains of RACK1 and S1248 of IGFR (or corresponding S1275 of IR) together with Y1250/Y1251 of IGFR (which have no counterpart in IR; Kiely et al., 2005; Zhang et al., 2006). Thus, although RACK1 does interact with IR, there is clear potential for preferential interaction with IGFR.

The mechanism of involvement of RACK1 in regulation of focal adhesions is not yet clear. It was reported that RACK1 interacted with Src, SHP2, and p85 in mouse embryonic fibroblasts, and that over-expression of RACK1 inhibited IGF-1-induced Akt phosphorylation and reduced its anti-apoptotic effect but enhanced cellular proliferation (Kiely et al., 2002). The combination of adhesion and IGF-1 signals led to formation of a complex containing IGFR, $\beta_{1}$ integrin, and RACK1, together with phosphorylated Shc, Src, SHP2, and IRSs. It was proposed that the IGFR-dependent scaffolding function of RACK1 regulates Akt activity and promotes turnover of focal adhesions (Kiely et al., 2005). RACK1 was constitutively associated with the phosphatase PP2A in serum-starved cells, and IGF-1-induced ligation of $\beta_{1}$ integrin was accompanied by dissociation of PP2A (Kiely et al., 2006). The WD7 domain of RACK1 is essential for binding both PP2A and $\beta_{1}$ integrin and thus for IGF-1-mediated cell migration and proliferation (Kiely et al., 2008). Recent data suggest that RACK1 interacts directly with FAK, and this association is regulated by IGF-stimulated, c-Abl-mediated tyrosine phosphorylation to facilitate adhesion signaling (Kiely et al., 2009). It is well known that FAK is tyrosinephosphorylated in response to clustering of integrins, and that IGF-1 and insulin induce dephosphorylation.

In separate studies RACK1 was reported to interact with IGFR, $\mathrm{PKC}$, and $\beta_{1}$ integrin in response to IGF-1 and phorbol ester 
stimulation in NIH3T3 fibroblasts. Over-expression of RACK1 reduced IGF-1-induced cell growth and enhanced cell spreading, accompanied by increased tyrosine phosphorylation of FAK but no effect on IRS/PI3K and Shc/MAP kinase pathways (Hermanto et al., 2002). Subsequently, RACK1-mediated STAT3 activation was implicated in insulin and IGF-1-induced anchorage-independent growth and protection from apoptosis (Zhang et al., 2006).

It has been reported that splice variants of $\beta_{1}$ integrins selectively modulate IGFR signaling in response to IGF stimulation, forming different complexes with IGFR and IRS-1 $\left(\beta_{1 \mathrm{~A}}\right)$ or Gab1 and SHP2 ( $\beta_{1 C}$; Goel et al., 2004). In prostate cancer cells, expression of $\beta_{1 \mathrm{~A}}$ was required for IGFR mitogenic and transforming activities, and colocalized with IGFR in focal contacts. However in the presence of $\beta_{1 \mathrm{C}}$ IGFR did not localize to focal contacts and remained diffuse on the cell surface (Goel et al., 2005). To add further complexity, the composition of RACK1 scaffolding complexes and effects on IGF-1 signaling appear to be different in transformed and untransformed cells. In a cardiomyocyte cell line, IGF-1 promoted recruitment of Src and PKC $\alpha$ to RACK1 independently of association with IGFR, while still influencing cell survival, adhesion and migration (O'Donovan et al., 2007).

Interactions between IGFR and adhesion signaling pathways are not confined to $\beta_{1}$ integrins. In $\mathrm{CHO}$ and smooth muscle cells $\alpha_{V} \beta_{3}$ integrin modulates IGFR-linked signaling and IGFstimulated cellular growth and migration responses, in association with integrin-associated protein and the transmembrane glycoprotein SHPS-1. Ligand occupancy influences recruitment of SHP2 to IGFR and thereby modulates the duration of IGFR phosphorylation (Clemmons and Maile, 2003). SHPS-1 is phosphorylated by IGFR and acts as scaffold for recruitment of $\alpha_{V} \beta_{3}$ integrinassociated SHP2 and Shc (Clemmons and Maile, 2005; Clemmons et al., 2007). These interactions may modulate IGFR signaling in response to increased $\alpha_{V} \beta_{3}$ integrin ligands in hyperglycemic stress.

\section{$\beta$-ARRESTINS}

$\beta$-Arrestins have primarily been studied in relation to signaling by GPCRs, in which context they act as scaffolds interacting with ERK, Akt, and PI3K (Lefkowitz and Shenoy, 2005; DeWire et al., 2007) and participate in reciprocal regulation of GPCRs and RTKs (Hupfeld and Olefsky, 2007). However, $\beta$-arrestins may have a more direct role in IR/IGFR signaling. It has been reported that $\beta$-arrestins promote clathrin-mediated endocytosis of ligandoccupied IGFR, enhancing activation of ERK and DNA synthesis (Lin et al., 1998) and, more controversially, that $\beta$-arrestin 1 can couple IGFR to activation of PI3K and ERK independently of TK activity (Povsic et al., 2003; Girnita et al., 2007). There is also evidence that $\beta$-arrestin 2 facilitates Akt activation by scaffolding Akt and Src to IR, and that deficiency of this signaling complex in mice contributes to development of insulin resistance (Luan et al., 2009). There have been occasional reports that $G$ proteins themselves may participate in IR/IGFR signaling, and that interaction of IR and IGFR with distinct $G$ proteins may contribute to insulin/IGF signaling specificity. It was proposed that Gaq plays a role in IR signaling to GLUT4, acting upstream of PI3K (Imamura et al., 1999) while Gi and $\beta$-arrestin 1 participate in IGFR mitogenic signaling, but not metabolic or mitogenic IR signaling (Dalle et al., 2001).

\section{CYTOHESINS}

A role in insulin signaling has also been proposed for cytohesins, which otherwise act as guanine nucleotide exchange factors for ARF family GTPases (involved in cytoskeletal organization and integrin activation and signaling). Cytohesins have a modular domain structure, including a PH domain and Sec7 GEF domain, with potential to act as molecular scaffolds (Kolanus, 2007). Cytohesins were implicated by genetic studies in insulin signaling in Drosophila, acting upstream of $\mathrm{PI} 3 \mathrm{~K}$ and required for regulation of Akt and FOXO (Fuss et al., 2006). Cytohesin function was also shown to be required for FOXO-dependent gene regulation in mammalian liver, and inhibition resulted in hepatic insulin resistance (Hafner et al., 2006). It was proposed that cytohesins facilitate formation of the IR/IRS complex and thus to activation of downstream metabolic signaling cascades. Cytohesins are binding partners for the CNK family of scaffold proteins, which in turn have multiple protein interaction domains including $\mathrm{PH}$ and PDZ domains and contribute to Ras activation by Raf. Recent data identified the CNK1/cytohesin interaction as critical for activation of the PI3K/Akt pathway downstream of IR/IGFR, with evidence that CNK1 acts as a positive regulator of insulin signaling by facilitating insulin-induced membrane recruitment of cytohesin, thereby modulating Arf signaling to PtdIns 4-phosphate 5-kinases (PIP5Ks) and promoting local generation of the PI3K substrate PtdIns(4,5) P2 (Lim et al., 2010).

\section{IR- AND IGFR-SPECIFIC INTERACTORS}

For many growth factors, direct recruitment of $\mathrm{SH} 2$ domaincontaining proteins to autophosphorylated RTKs initiates signaling pathways. In the case of insulin and IGF signaling, this role is predominantly taken by phosphorylated IRSs and Shc, but activated IR/IGFR also directly recruit some of the same adaptors as well as other proteins that may participate in signaling or modulate receptor function. Among these are p85 and SHP2 which bind to the CT tail and RasGAP (GTPase activating protein) which binds to the JM region (Staubs et al., 1994; Rocchi et al., 1996). These interactions appear to be at phosphorylation sites that are conserved between IR and IGFR, rather than those that are receptor-specific. Binding of p85 directly to IR/IGFR is probably of minor importance compared to recruitment by phosphorylated IRSs and although it may allow tyrosine phosphorylation of p85 and p110 this is of uncertain significance (reviewed in Shepherd et al., 1998). Proteomic approaches have recently been used to characterize the spectrum of $\mathrm{SH} 2$ domains that bind to putative tyrosine phosphorylation sites on IR and IGFR, although these studies took no account of whether these sites are actually phosphorylated upon receptor activation nor of the relative affinities of interactions at different sites. Potential IGFR interactors included both substrates and non-substrates, most of which could bind also to EGFR and FGFR (PI3K, Src family kinases, PLC $\gamma$, Grb7/10/14, SH2-B, JAKs, STATs, Crk) although interaction of Cbl appeared to be unique to IGFR (Kaushansky et al., 2008). A separate study reported that the major difference between IGFR and IR was in their potential to recruit SHP2 (Hanke and Mann, 2009). It has 
also been reported that 14-3-3 interacts specifically with IGFR, via S1283, but not with IR (Furlanetto et al., 1997), and this may contribute to anti-apoptotic signaling (Peruzzi et al., 1999) and transformation pathways (Spence et al., 2003). A PDZ protein IIP1/GIPC, identified as a binding partner for the C-terminal tail of IGFR but not IR (Ligensa et al., 2001), was suggested to couple IGFR to $G_{i}$ (Booth et al., 2002) and more recently was implicated in ROS generation (Choi et al., 2010). Thus there are a number of hints that receptor-specific interactors may contribute to signaling specificity of IGFR compared to IR, but these have not been studied in sufficient depth to establish that they play an important role in vivo.

\section{OTHER SIGNALING PATHWAYS}

Several other signaling mechanisms have been implicated in insulin/IGF action, including activation of non-RTKs, redox regulation of phosphatases, and generation of alternative phosphoinositides. In most of these cases molecular details of the receptor interactions that initiate signaling are unclear, making it difficult to assess whether there is specificity for IR or IGFR.

\section{NON-RECEPTOR TYROSINE KINASES}

JAKs and their transcription factor substrates STATs are most commonly associated with signaling by cytokine receptors (O'Shea et al., 2002). However, several groups have reported phosphorylation and activation of JAK1 and/or JAK2 in response to IR and/or IGFR stimulation, albeit with inconsistencies in detail (GiorgettiPeraldi et al., 1995; Gual et al., 1998; Takahashi et al., 1999; Zong et al., 2000; Carvalheira et al., 2003; Yadav et al., 2005). Recruitment of JAKs may be by interaction with phosphorylated IR/IGFR (Gual et al., 1998), with Grb2 (Giorgetti-Peraldi et al., 1995) or with IRSs (Velloso et al., 1998). Activation of JAKs by insulin/IGF was accompanied by phosphorylation of one or more STATs (Velloso et al., 1998; Takahashi et al., 1999; Zong et al., 2000; Carvalheira et al., 2003; Yadav et al., 2005), but STAT5B was also reported to be phosphorylated as a direct substrate of IR/IGFR TKs independently of JAKs (Chen et al., 1997; Sawka-Verhelle et al., 2000). JAKs may also phosphorylate IRS-1, on distinct sites from the IR/IGFR TKs (Gual et al., 1998; Li et al., 2007). Although there is potential for JAK/STAT pathways to augment insulin/IGF signaling in some cell types (Himpe and Kooijman, 2009) there is little evidence that they are of widespread importance in mediating insulin/IGF action. However, SOCS proteins, which act as feedback inhibitors of JAK/STAT pathways, also bind to IR/IGFR and inhibit IRS phosphorylation and downstream signaling (Howard and Flier, 2006; Lebrun and Van Obberghen, 2008; Himpe and Kooijman, 2009) and this may provide a mechanism of cross-talk between cytokine and insulin/IGF signaling pathways.

Src family kinases (Src, Fyn, and Yes) are involved in signaling by and regulation of diverse RTKs (Bromann et al., 2004). Studies in a variety of cell lines have shown that rapid activation of Src family kinases by both IGF-1 and insulin contributes significantly to phosphorylation of Shc and downstream mitogenic responses (Boney et al., 2000, 2001; Shumay et al., 2002; Sekharam et al., 2003; Criswell et al., 2005; Lieskovska et al., 2006). Activation of Src family kinases by RTKs may in some cases involve recruitment by interaction between $\mathrm{SH} 2$ domains and autophosphorylated receptors, but in others the mechanisms appear to be more complex (Bromann et al., 2004). The mechanism of activation by insulin/IGF is unclear, although it is known that Fyn associates with phosphorylated IRS-1 (Sun et al., 1996). It has also been suggested that SHP2 and SHPS-1 may play a role as scaffolds in recruitment and activation of Src by IGFR (Lieskovska et al., 2006). Src family kinases augment signaling from RTKs in a number of ways, participating in pathways required for DNA synthesis, motility and survival (Bromann et al., 2004).

Both insulin and IGF-1 have been reported to activate c-Abl (Frasca et al., 2007; Srinivasan et al., 2008; Genua et al., 2009; Kiely et al., 2009), a non-receptor cytoplasmic TK implicated in the regulation of cell growth, survival, and morphogenesis by growth factors and adhesion (Sirvent et al., 2008). In HepG2 and MCF-7 cells, c-Abl was found to be specifically activated by insulin but not IGF-1, while inhibition of c-Abl modulated effects of insulin but not IGF-1, attenuating stimulation of the Akt/GSK3 cascade and glycogen synthesis while paradoxically enhancing its stimulation of ERK activation, proliferation, and migration (Frasca et al., 2007). It appeared that effects of c-Abl were mediated in part by FAK (Genua et al., 2009). In breast cancer cells, c-Abl was activated by IGF-1 and was required for IGF-1-stimulated cell cycle progression, mediated in part by phosphorylation of STAT3 (Srinivasan et al., 2008). The mechanism of activation of c-Abl was not investigated in these studies, but in other cells c-Abl is activated downstream of Src family kinases (Bromann et al., 2004). It is unclear whether involvement of c-Abl in insulin/IGF signaling is specific to the cell lines studied.

\section{REDOX REGULATION: PTPS AND PTEN}

The phosphatases that reverse the actions of protein and lipid kinases obviously play important roles in IR/IGFR signaling. PTP1B has been identified as a key phosphotyrosine phosphatase responsible for dephosphorylating IR/IGFR and IRSs (Dube and Tremblay, 2005) although other phosphatases may also be active in this regard, including SHP2 (Myers et al., 1998). The lipid phosphatases PTEN and SHIP2 both contribute to termination of phosphoinositide signaling, by dephosphorylating PtdIns(3,4,5)P3 at the 3 and 5 positions respectively (Vinciguerra and Foti, 2006). The question then arises whether the activity of these phosphatases is regulated in ways that could sensitize insulin/IGF signaling. Work in several laboratories has shown that activation of IR/IGFR (and certain other RTKs) promotes generation of reactive oxygen and nitrogen species which, by reversible oxidation of active-site cysteine residues, inhibit phosphatases including PTP1B and PTEN and thereby potentiate the effects of tyrosine phosphorylation and PI3K activation (Droge, 2005; Goldstein et al., 2005; Rhee et al., 2005; Ross et al., 2007; Vardatsikos et al., 2009; Hsu and Meng, 2010). Much of the data supporting this concept comes from manipulation of cultured cells, and even then the investigation of redox-based regulation is technically challenging (JanssenHeininger et al., 2008). However there is evidence from mouse knockout models that ROS enhance insulin sensitivity in vivo (Loh et al., 2009). The NAD(P)H oxidase homolog Nox4 has been identified as a likely source of insulin/IGF-stimulated $\mathrm{H}_{2} \mathrm{O}_{2}$ generation (Mahadev et al., 2004; Meng et al., 2008) but the mechanisms linking IR/IGFR signaling to Nox4 remain obscure. It has been 
reported that the PDZ domain protein GIPC is involved in mediating IGFR-induced ROS generation, possibly by inhibiting receptor internalization (Choi et al., 2010). However, GIPC was originally identified as a binding partner for the C-terminal tail of IGFR but not IR (Ligensa et al., 2001) and it is difficult to reconcile this specificity with involvement in ROS generation that appears to be similarly triggered by both receptors. Many questions regarding the mechanism and significance of ROS generation by IR/IGFR therefore remain to be answered.

\section{OTHER PHOSPHOINOSITIDES}

Additional to the well-established role of PtdIns(3,4,5)P3 generated by Class Ia PI3Ks, other phosphoinositides generated by class II and class III PI3Ks and PIKfyve may play roles in signaling (Shisheva, 2008a; Falasca and Maffucci, 2009). It has been reported that class II PI3Ks, whose sole product in vivo is believed to be PtdIns 3-P, are required for insulin signaling to glucose transport (Falasca et al., 2007) and for regulation of gene expression in pancreatic $\beta$-cells (Leibiger et al., 2010a). Activation of PI3K-C2 $\alpha$ by insulin apparently involves its recruitment to the plasma membrane mediated by the small GTPase TC-10 (a component of the CAP/Cbl pathway, discussed above; Falasca et al., 2007). PIKfyve, binds to PtdIns 3-P via its fyve domain and synthesizes PtdIns(3,5)P2 and PtdIns 5-P. PIKfyve is phosphorylated and activated by Akt but its mechanism of involvement in GLUT4 translocation is unclear (Berwick et al., 2004). Dysfunction of PIKfyve produces endosome enlargement and cytoplasmic vacuolation (Shisheva, 2008b), suggesting that it may have a general role in maintaining subcellular membrane compartments rather than a specific role in insulin signaling. To date, it appears that class II PI3K and PIKfyve have only been examined in the context of insulin action on glucose transport, and it is unclear whether these enzymes and their lipid products might play wider roles in insulin/IGF actions.

\section{RECEPTOR TRAFFICKING}

As well as activating signaling pathways, autophosphorylation of IR/IGFR triggers internalization of the ligand/receptor complex, mainly via clathrin-coated pits although receptors are also found associated with caveolae (Foti et al., 2004). One role of this traffic is in signal termination, through dissociation and/or degradation of ligand in the intracellular endosome/lysosome system. The receptors are largely recycled, although persistent occupancy/internalization can increase receptor degradation (down regulation; Di Guglielmo et al., 1998). However, there is evidence that receptor internalization also plays an active role in signaling (Smith et al., 1997; Foti et al., 2004).

\section{RECEPTORS IN ENDOSOMES}

Several studies have shown that IR/IGFR-mediated phosphorylation of Shc, but not IRSs, is dependent on receptor internalization (Biener et al., 1996; Ceresa et al., 1998; Chow et al., 1998; Hamer et al., 2002). IR-A internalizes more rapidly than IR-B (Vogt et al., 1991; Yamaguchi et al., 1991; Giudice et al., 2011) and this could lead to more effective phosphorylation of Shc. The mechanism underlying the different internalization rates of IR isoforms is unclear, but might involve their differential autophosphorylation (Kellerer et al., 1992) and/or differential exposure of NPxY or LL motifs (Foti et al., 2004). Internalized endosomal IR remain active, and endosomes may even be the principal site of IRS-1 phosphorylation and PI3K activation as well as signaling to Shc/ERK pathways (Di Guglielmo et al., 1998). Slow-dissociating, high affinity insulin analogs induce sustained activation of IR, and this is associated with increased receptor internalization, Shc phosphorylation and ERK activation that may reflect signaling from intracellular sites (Hansen et al., 1996; Rakatzi et al., 2003). It has also been reported that internalization and recycling of IGFR is necessary for sustained phosphorylation of Akt (Romanelli et al., 2007). Surprisingly there have been few reports directly comparing the internalization kinetics and intracellular itineraries of IR and IGFR. One study with receptors over-expressed in rat-1 fibroblasts concluded that IGF-1 internalizes more slowly than insulin and dissociates more slowly from its receptor in the acidifying endosome, but did not attempt to relate these characteristics to intracellular signaling pathways (Zapf et al., 1994).

\section{RECEPTORS IN NUCLEI}

More controversially, studies going back several decades have suggested that IR are found in cell nuclei (Goldfine et al., 1982; Podlecki et al., 1987; Smith et al., 1997). There is also evidence for insulin/IGF-1 induced nuclear localization of IRSs (Sun et al., 2003; Wu et al., 2003; Chen et al., 2005). It was initially suggested that nuclear IR might specifically mediate mitogenic responses, although it is now known that downstream signaling components including activated Akt and ERK can also traffic to the nucleus, so that nuclear localization of receptors per se is not necessary for induction of nuclear events. However, the idea persists that functional IR/IGFR are localized within cell nuclei. Recently it was reported that IR signaling complexes are recruited to specific insulin-inducible gene loci (Nelson et al., 2011) and that nuclear IGFR is phosphorylated in response to ligand, binds to chromatin and acts directly as a transcriptional enhancer (Aleksic et al., 2010; Sehat et al., 2010). The pathways by which activated receptors might traffic to the nucleus, let alone associate with intranuclear chromatin, are unclear. Sumoylation may play a role in nuclear targeting of IGFR (Sehat et al., 2010).

\section{UBIQUITINATION}

Ubiquitination plays a key role in regulating the trafficking and degradation of many proteins (Acconcia et al., 2009; Zwang and Yarden, 2009), with potential to act as an inducible, reversible, and flexible signaling device depending on whether proteins are mono- or poly-ubiquitinated and on how ubiquitin chains are linked together (Kirkin and Dikic, 2007; Ikeda and Dikic, 2008). Several different mechanisms have been proposed for ubiquitination of IR/IGFR, but the sites and nature of modifications are poorly characterized. Grb10 has been implicated in regulation of ligand-induced ubiquitination and stability of both IR and IGFR, mediated by E3 ubiquitin ligase Nedd4 (Vecchione et al., 2003; Ramos et al., 2006; Huang and Szebenyi, 2010). This mechanism may contribute along with direct inhibition of receptor TK activity to negative regulation of IR/IGFR signaling by Grb10. Paradoxically however, insulin and IGF signaling and cell surface expression of IR and IGFR are reduced in Nedd4-null mice, suggesting that in vivo Nedd4 exerts a positive effect on signaling (Cao et al., 2008). 
This may in part reflect an influence of Nedd4 on Grb10 abundance (Cao et al., 2008) although there is no evidence that Grb10 itself is ubiquitinated by Nedd4 (Vecchione et al., 2003).

The E3 ubiquitin ligase activity of Cbl proteins has been implicated in negative regulation of many different receptors with intrinsic or associated TK activity (Schmidt and Dikic, 2005; Thien and Langdon, 2005), and there is evidence that Cbl, recruited by APS, catalyzes ubiquitination of IR and IGFR with a role in endocytosis (Ahmed et al., 2000; Kishi et al., 2007; Sehat et al., 2008). A third E3 ubiquitin ligase, Mdm2, has been implicated in degradation of IGFR (Girnita et al., 2003) following recruitment dependent on $\beta$-arrestin (Girnita et al., 2005, 2007). It is possible that distinct patterns of ubiquitination mediated by different ligases may have different consequences (Sehat et al., 2008) and it has been proposed that under some circumstances ubiquitination plays a positive role in signaling by IGFR and IR (Sehat et al., 2007; Suzuki et al., 2009). Downstream of the IR, recent evidence suggests that ubiquitination of GLUT4 may act as signal for trafficking from the endosomal/TGN system to a specific intracellular storage compartment, facilitating insulin-stimulation of glucose transport (Lamb et al., 2010).

\section{NEGATIVE AND FEEDBACK REGULATION}

Insulin signaling is susceptible to a variety of controls reflecting feedback from the insulin signaling pathway itself and crosstalk from other pathways. These mechanisms can in principle be receptor or pathway-specific, so that insulin/IGF resistance can be selective in terms of affected tissues and biological responses.

\section{PHOSPHORYLATION}

Prominent among feedback regulatory mechanisms is the phosphorylation of IR/IGFR and IRSs by serine/threonine kinases. Both IR and IGFR are susceptible to multisite serine phosphorylation induced by insulin/IGF via unidentified kinases, or by activation of PKCs (Pillay et al., 1991; Tavare et al., 1991; Coghlan et al., 1994; Liu and Roth, 1994). Serine phosphorylation of IR may contribute to development of insulin resistance, for instance as a consequence of hyperglycemia (Kellerer and Haring, 1995). Serine phosphorylation of IGFR may result in 14-3-3 binding, affecting both signaling and receptor turnover (Furlanetto et al., 1997; Spence et al., 2003). However, the sites, mechanisms, and consequences of IR/IGFR serine/threonine phosphorylation have never been well defined and there have been few recent studies in this area.

In contrast, the phosphorylation of IRS-1 has been intensively studied over the last two decades, in terms of identification of specific phosphorylation sites and responsible kinases and elucidation of functional consequences (Boura-Halfon and Zick, 2009; Sun and Liu, 2009). IRS-1 is a substrate for phosphorylation by several kinases that lie downstream in the insulin signaling pathway, including Akt/PKB, GSK3, and S6K1 as well as kinases activated by other signals, including AMPK, PKCs, Jnk, and IKK $\beta$. Most commonly, serine/threonine phosphorylation inhibits IRS-1 function (by inhibiting overall tyrosine phosphorylation, promoting degradation, or inhibiting association of adaptor proteins at specific sites) although phosphorylation at certain sites can potentiate IRS1 tyrosine phosphorylation. However, given the complexity arising from the number of phosphorylation sites and the potential for interaction between them, understanding is far from complete. Serine phosphorylation of IRS-2 has so far been less studied, but is likely to be equally complex (Boura-Halfon and Zick, 2009; Fritsche et al., 2011). It would be expected that insulin resistance secondary to impairment of IRS function would affect mainly the PI3K/Akt pathway and less so the Ras/ERK pathway which can be alternatively activated via Shc. Indeed inhibition of IRS association with receptors may even potentiate Shc/Ras signaling by relieving competition for binding to and phosphorylation by IR/IGFR.

Subversion of normal feedback and cross-talk IRS regulatory mechanisms by lipid metabolites, adipokines, or inflammatory mediators is believed to contribute to obesity-associated insulin resistance (Boura-Halfon and Zick, 2009; Sun and Liu, 2009). However, there is evidence that the most deleterious defects underlying common states of insulin resistance are independent of IRSs (Hoehn et al., 2008; Li et al., 2010; Ng et al., 2010) and it seems clear that additional regulatory mechanisms remain to be elucidated. Recent evidence has revealed mTOR-dependent phosphorylation of Grb10 as a key mechanism of negative regulation of IR/IGFR signaling (Hsu et al., 2011; Yu et al., 2011).

\section{O-GLcNAcylation}

Reversible modification of protein serine/threonine residues can occur by $O$-GlcNAcylation, potentially providing a mechanism of cross-talk with phosphorylation (Copeland et al., 2008; Zeidan and Hart, 2010). A large number of cytoplasmic and nuclear proteins including components of signaling pathways and transcription factors are susceptible to O-GlcNAcylation, although relatively few specific sites have been mapped (Copeland et al., 2008). In some proteins $O$-GlcNAc modification seems to occur at the same sites as are susceptible to phosphorylation, and it can variously block or mimic effects of phosphorylation depending on substrate and site, thereby regulating protein stability and subcellular localization and protein-protein interactions (Slawson et al., 2010; Zeidan and Hart, 2010). Reflecting the origin of the $O$-GlcNAc moiety as a product of the hexosamine biosynthetic pathway, it has been proposed that O-GlcNAcylation is a nutrient and stress-sensitive modification, although it is not the only mechanism of hyperglycemia induced insulin resistance (Copeland et al., 2008). Following insulin stimulation, O-GlcNAc transferase (OGT) is recruited to $\operatorname{PtdIns}(3,4,5) \mathrm{P} 3$ in the plasma membrane via a novel phosphoinositide binding domain (Yang et al., 2008) although it has also been reported that OGT is directly phosphorylated and activated by IR (Whelan et al., 2008). Several components of insulin signaling pathways, including IR $\beta$, IRS-1, and Akt, are transiently modified by $O$-GlcNAc following insulin stimulation, which in turn modulates their serine phosphorylation (IRS-1 increased, Akt decreased) and attenuates insulin signal transduction (Yang et al., 2008). IRS-1 is O-GlcNAc modified at multiple sites in close proximity to $\mathrm{SH} 2$ domain binding motifs (Klein et al., 2009), and pharmacological elevation of $O$ GlcNac inhibited tyrosine phosphorylation of at least one PI3K binding motif (Whelan et al., 2010). A proper understanding of the role of $O$-GlcNAcylation in insulin signaling pathways must await a more detailed description of the sites and consequences of 
$O$-GlcNAc modification, and the circumstances under which this is modulated.

\section{OTHER MECHANISMS}

Several other mechanisms have been implicated in modulation of insulin/IGF signaling (Youngren, 2007). Some of these, such as the recruitment of SOCS proteins to receptors and IRSs (Lebrun and Van Obberghen, 2008) or actions of PKCs (Sampson and Cooper, 2006; Farese and Sajan, 2010) primarily reflect cross-talk from other pathways. The efficiency of signaling via the PI3K pathway is critically dependent on the balance of expression of PI3K regulatory and catalytic subunits. Free p85 regulatory subunits inhibit signaling by at least two mechanisms, first by competing with active PI3K heterodimer for binding sites on IRSs, and second by facilitating activation of JNK (Taniguchi et al., 2006). A genome-wide scanning approach identified multiple negative regulators of insulin signaling including diverse phosphatases and kinases together with some previously uncharacterized proteins whose mechanism of action remains to be determined (Huang et al., 2009).

Receptor-specific interactions with plasma membrane glycoproteins has also been linked to efficiency of insulin signaling. CEACAM-1 (also known as C-CAM and HA4/pp120), a cell adhesion molecule with ecto-ATPase activity that is highly expressed in liver, is a specific IR substrate that has been implicated in positive regulation of IR endocytosis and insulin clearance (Najjar, 2002; DeAngelis et al., 2008). Plasma cell antigen-1 (PC-1; also known as ENPP1), an ecto-nucleotide pyrophosphatase and phosphodiesterase, binds to the connecting domain of the IR alpha-subunit that is located in residues 485-599 and inhibits insulin-induced TK activity. Overexpression or overactivity of PC-1 has been proposed to contribute to insulin resistance (Goldfine et al., 2008). There is no evidence that CEACAM-1 or PC-1 interact also with IGFR.

\section{CONCLUSION}

It is beyond question that insulin and IGFs fulfill fundamentally different physiological roles in vivo, and this has led to a widespread perception that these distinct actions are somehow dependent on divergent signaling properties of the respective receptors, IR favoring metabolic responses and IGFR growth-promoting actions. However when studied in defined cellular systems in vitro, the actions of insulin and IGFs appear very similar, although most studies have necessarily relied on cultured cells of rather nondescript phenotype rather than systems that preserve the complex differentiated phenotypes that typify responses in vivo. The differences that have been observed in vitro are largely quantitative rather than qualitative, and related at least in part to the levels of IR and IGFR expression. Certainly there is no convincing evidence that IR can mediate effects that cannot also be mediated by IGFR, or vice versa, and the issue of signaling specificity then comes down to the relative efficiency with which the receptors engage different signaling pathways that contribute to "metabolic" or "mitogenic" outcomes. It is an artificial question to ask how the activities of IR and IGFR compare when given equal opportunity (equal receptor expression and equivalent ligand stimulation in defined cell backgrounds), because this situation never obtains in vivo, but this is the only basis on which similarities and differences in intrinsic activity can be properly defined. One recent study that adopted this approach in relation to regulation of gene expression by insulin and IGF-1 in brown adipocytes concluded that IR and IGFR act as identical portals in terms of signaling, and that quantitative differences between the effects of insulin and IGF-1 reflected the expression levels of the respective receptors and/or ligand profiles (Boucher et al., 2010b).

This review examines the question of whether there are differences between IR and IGFR at the level of receptor-proximal intracellular signaling. It is well accepted that the canonical PI3K/Akt and Ras/ERK pathways, initiated by the tyrosine phosphorylation of IRSs and Shc, are central in mediating actions of both insulin and IGFs. The PI3K/Akt pathway regulates a broad spectrum of responses, both metabolic and growth-related (as evidenced by the association of aberrant activity of both PI3K and Akt with various cancers), while the Ras/MAPK pathway is important in regulating cell proliferation and differentiation but is not involved in acute metabolic regulation. Recent reviews of insulin/IGF signaling have focused very much on the canonical pathways (Adams et al., 2004; Cohen, 2006; Taniguchi et al., 2006; Laviola et al., 2007). However, as reviewed here, many other components have been implicated in signaling, either independently of or as modulators of the canonical pathways, or as regulators of receptor activation and trafficking (Figure 2). In many cases the contributions of these components have been studied only under limited conditions and it remains unclear whether their roles are specialized, and relevant only to particular responses in particular tissues, or more general. Some, like the APS/CAP/Cbl pathway, have been studied only in the context of metabolic actions of insulin in adipocytes, while others such as RACK1, have been studied mainly in relation to actions of IGFs on migration and proliferation of fibroblasts. These specificities may have more to do with the functions of differentiated cells than the signaling competences of the receptors, but the issue is largely theoretical unless APS and IGFR, or RACK1 and IR, are shown to be significantly co-expressed in cells in vivo. Only a very few interactions have been reported that appear truly receptorspecific, notably those of IIP-1/GIPC and 14-3-3 with IGFR, but the functional significance of these interactions and their role in mediating actions of IGFs is unknown. It is possible that other receptor-specific interactors may emerge from proteomic studies. Certainly there is more than sufficient divergence in the primary sequences of IR and IGFR, particularly in the JM and CT regions, to allow receptor-specific covalent modification by phosphorylation, $\mathrm{O}$-GlcNAcylation, or ubiquitination, and such modification might in turn mediate specific interactions that could influence receptor activity or subcellular localization.

In principle, differential mediation of "metabolic" and "mitogenic" responses by IR and IGFR might reflect differential phosphorylation of substrates in the canonical pathways or selective engagement of accessory pathways or modulators. As reviewed elsewhere (Jensen and De Meyts, 2009), the mechanisms and kinetics of ligand binding determine the kinetics of activation and intracellular trafficking of receptors, which in turn can influence the relative phosphorylation of IRSs and Shc in a ligand-dependent manner. As detailed here, there is also evidence that IR interacts more effectively than IGFR with IRS-1 while the converse may be 


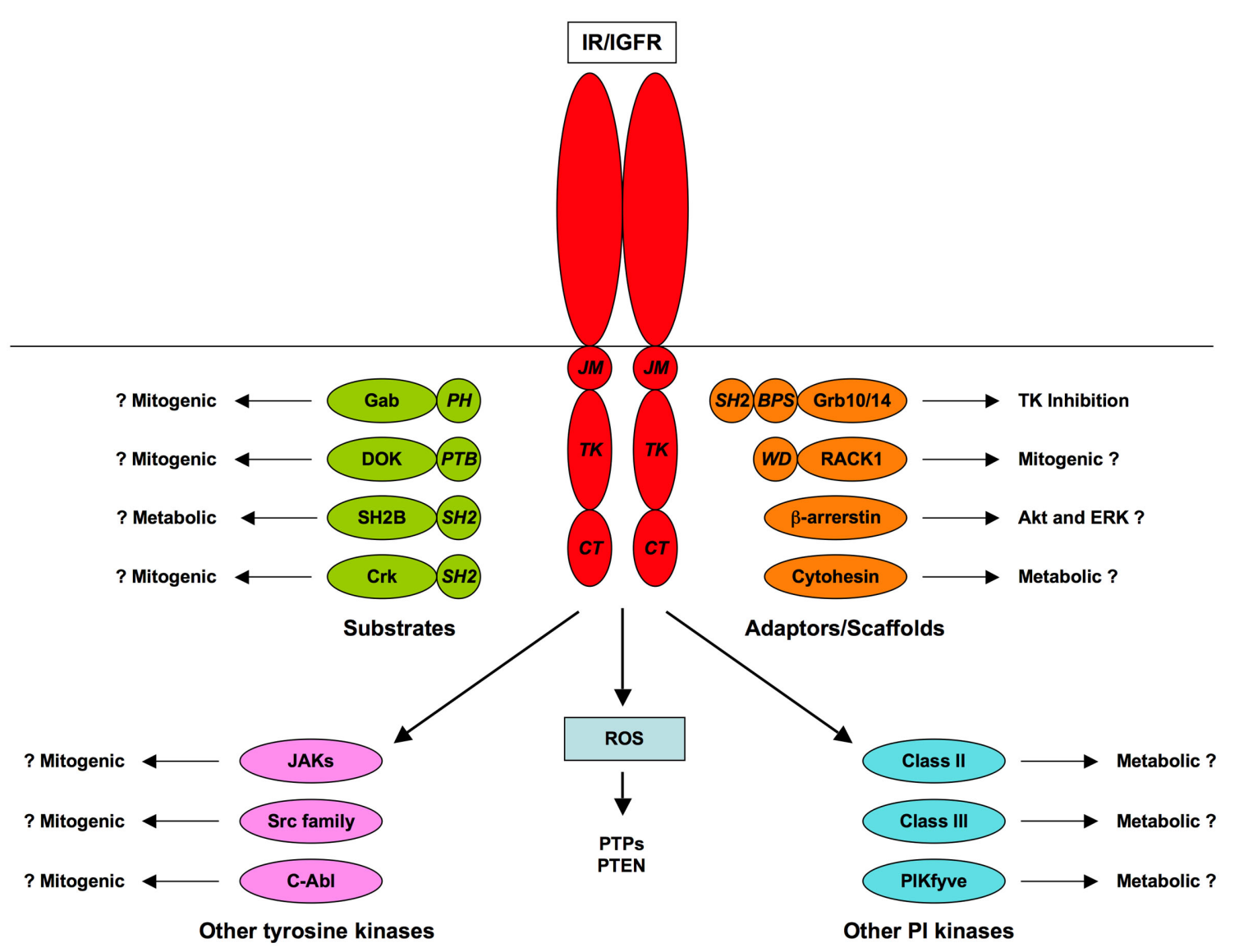

FIGURE 2 | Accessory components of IR/IGFR signaling. Substrates, scaffolds, and pathways additional to the canonical PI3K/Akt and Ras/ERK pathways are shown, with protein-protein interaction domains (JM, juxtamembrane; TK, tyrosine kinase; $C T$, carboxyl-terminal; PTB, phosphotyrosine-binding; $\mathrm{PH}$, pleckstrin homology, $\mathrm{SH} 2, \mathrm{Src}$ homology-2; $B P S$, between $\mathrm{PH}$ and $\mathrm{SH} 2 ; \mathrm{WD}, \mathrm{W}-\mathrm{D}$ (Trp-Asp) dipeptide repeat). true for IRS-2 and Shc, and this may be reinforced by receptorpreferential phosphorylation of different sites on these substrates. All of these factors might contribute to more effective "mitogenic" signaling by IGFR compared to IR. In relation to accessory and modulatory pathways, the proposed mechanism of interaction of RACK1 would be expected to favor IGFR over IR, but Gabs, DOKs, $\mathrm{SH} 2 \mathrm{Bs}$, and Grbs would not be expected to discriminate between the receptors. Non-RTKs of the JAK, Src, and Abl families, which may contribute to mitogenic responses, can apparently be activated by both IR and IGFR but not enough is known about the activation mechanisms to indicate whether IGFR might activate more effectively than IR. The roles and mechanisms of interaction of scaffold proteins such as $\beta$-arrestins and cytohesins are even less clearly defined.

The most that can be said with certainty is that the signaling mechanisms of IR and IGFR are very much more similar than different, and that cellular context, rather than intrinsic receptor activity, is the major determinant of whether responses to insulin and IGFs are perceived as "metabolic" or "mitogenic." The question remains whether subtle differences in signaling between IR and IGFR also contribute to the specificity of action of insulin and IGFs. Resolution of this issue may have to await the further development of methods for global quantification of the phosphorylation, interaction, and activity of signaling networks and for mathematical modeling of the resulting large datasets. Such systems approaches are increasingly being applied in an attempt to relate biological outcomes to the complex kinetics of activation of interacting signaling pathways (Del Rosario and White, 2010; Morris et al., 2010b; Vinayagam et al., 2011). Although this field is still in its infancy, modeling has already illustrated how subtle differences in the activity of individual signaling components and cross-talk between signaling pathways can affect biological responses (Cedersund et al., 2008; Aldridge et al., 2009; Brannmark et al., 2010; Morris et al., 2011; Rowland et al., 2011). In the future it is to be expected that modeling will generate quantitative predictions and testable biological hypotheses about the operation of signaling networks, that will lead to better understanding of signaling specificity.

\section{ACKNOWLEDGMENTS}

Recent work in the Kenneth Siddle laboratory has been funded by BBSRC, MRC, and Diabetes UK. Kenneth Siddle is a member of the Medical Research Council Centre for Obesity and Related Metabolic Diseases (MRC-CORD). 


\section{REFERENCES}

Acconcia, F., Sigismund, S., and Polo, S. (2009). Ubiquitin in trafficking: the network at work. Exp. Cell Res. 315, 1610-1618.

Adams, T. E., Mckern, N. M., and Ward, C. W. (2004). Signalling by the type 1 insulin-like growth factor receptor: interplay with the epidermal growth factor receptor. Growth Factors 22, 89-95.

Ahmed, Z., and Pillay, T. S. (2003). Adapter protein with a pleckstrin homology (PH) and an Src homology 2 (SH2) domain (APS) and SH2-B enhance insulinreceptor autophosphorylation, extracellular-signal-regulated kinase and phosphoinositide 3-kinasedependent signalling. Biochem. J. 371, 405-412.

Ahmed, Z., Smith, B. J., Kotani, K., Wilden, P., and Pillay, T. S. (1999). APS, an adapter protein with a $\mathrm{PH}$ and $\mathrm{SH} 2$ domain, is a substrate for the insulin receptor kinase. Biochem. J. 341, 665-668.

Ahmed, Z., Smith, B. J., and Pillay, T. S. (2000). The APS adapter protein couples the insulin receptor to the phosphorylation of c-Cbl and facilitates ligand-stimulated ubiquitination of the insulin receptor. FEBS Lett. 475, 31-34.

Ahn, M. Y., Katsanakis, K. D., Bheda, F., and Pillay, T. S. (2004). Primary and essential role of the adaptor protein APS for recruitment of both c-Cbl and its associated protein CAP in insulin signaling. J. Biol. Chem. 279, 21526-21532.

Aldridge, B. B., Saez-Rodriguez, J., Muhlich, J. L., Sorger, P. K., and Lauffenburger, D. A. (2009). Fuzzy logic analysis of kinase pathway crosstalk in TNF/EGF/insulininduced signaling. PLoS Comput. Biol. 5, e1000340. doi:10.1371/journal.pcbi. 1000340

Aleksic, T., Chitnis, M. M., Perestenko, O. V., Gao, S., Thomas, P. H., Turner, G. D., Protheroe, A. S., Howarth, M., and Macaulay, V. M. (2010). Type 1 insulin-like growth factor receptor translocates to the nucleus of human tumor cells. Cancer Res. 70, 6412-6419.

Alvino, C. L., Mcneil, K. A., Ong, S. C., Delaine, C., Booker, G. W., Wallace, J. C., Whittaker, J., and Forbes, B. E. (2009). A novel approach to identify two distinct receptor binding surfaces of insulin-like growth factor II. J. Biol. Chem. 284, 7656-7664.

Amoui, M., Craddock, B. P., and Miller, W. T. (2001). Differential phosphorylation of IRS-1 by insulin and insulin-like growth factor I receptors in Chinese hamster ovary cells. J. Endocrinol. 171, 153-162.

Aronheim, A., Engelberg, D., Li, N., AlAlawi, N., Schlessinger, J., and Karin, M. (1994). Membrane targeting of the nucleotide exchange factor Sos is sufficient for activating the Ras signaling pathway. Cell 78, 949-961. Avruch, J. (2007). MAP kinase pathways: the first twenty years. Biochim. Biophys. Acta 1773, 1150-1160.

Backer, J. M., Shoelson, S. E., Weiss, M. A., Hua, Q. X., Cheatham, R. B., Haring, E., Cahill, D. C., and White, M. F. (1992). The insulin receptor juxtamembrane region contains two independent tyrosine/beta-turn internalization signals. J. Cell Biol. 118, 831-839.

Bailyes, E. M., Nave, B. T., Soos, M. A., Orr, S. R., Hayward, A. C., and Siddle, K. (1997). Insulin receptor/IGFI receptor hybrids are widely distributed in mammalian tissues: quantification of individual receptor species by selective immunoprecipitation and immunoblotting. Biochem. J. 327, 209-215.

Barres, R., Gonzalez, T., Le MarchandBrustel, Y., and Tanti, J. F. (2005). The interaction between the adaptor protein APS and Enigma is involved in actin organisation. Exp. Cell Res. 308, 334-344.

Barres, R., Gremeaux, T., Gual, P., Gonzalez, T., Gugenheim, J., Tran, A., Le Marchand-Brustel, Y., and Tanti, J. F. (2006). Enigma interacts with adaptor protein with $\mathrm{PH}$ and $\mathrm{SH} 2$ domains to control insulin-induced actin cytoskeleton remodeling and glucose transporter 4 translocation. Mol. Endocrinol. 20, 2864-2875.

Baudry, A., Lamothe, B., Bucchini, D., Jami, J., Montarras, D., Pinset, C., and Joshi, R. L. (2001). IGF-1 receptor as an alternative receptor for metabolic signaling in insulin receptor-deficient muscle cells. FEBS Lett. 488, 174-178.

Beitner-Johnson, D., Blakesley, V. A., Shen-Orr, Z., Jimenez, M., Stannard, B., Wang, L. M., Pierce, J., and LeRoith, D. (1996). The protooncogene product c-Crk associates with insulin receptor substrate-1 and 4PS. Modulation by insulin growth factor-I (IGF) and enhanced IGF-I signaling. J. Biol. Chem. 271, 9287-9290.

Beitner-Johnson, D., and LeRoith, D. (1995). Insulin-like growth factor-I stimulates tyrosine phosphorylation of endogenous c-Crk. J. Biol. Chem. 270, 5187-5190.

Belfiore, A., Frasca, F., Pandini, G., Sciacca, L., and Vigneri, R. (2009). Insulin receptor isoforms and insulin receptor/insulin-like growth factor receptor hybrids in physiology and disease. Endocr. Rev. 30, 586-623.

Bereziat, V., Kasus-Jacobi, A., Perdereau, D., Cariou, B., Girard, J., and Burnol, A. F. (2002). Inhibition of insulin receptor catalytic activity by the molecular adapter Grb14. J. Biol. Chem. 277, 4845-4852.

Berwick, D. C., Dell, G. C., Welsh, G. I., Heesom, K. J., Hers, I., Fletcher, L. M., Cooke, F. T., and Tavare, J. M. (2004). Protein kinase B phosphorylation of PIKfyve regulates the trafficking of GLUT4 vesicles. J. Cell. Sci. 117, 5985-5993.

Biener, Y., Feinstein, R., Mayak, M., Kaburagi, Y., Kadowaki, T., and Zick, Y. (1996). Annexin II is a novel player in insulin signal transduction. Possible association between annexin II phosphorylation and insulin receptor internalization. J. Biol. Chem. 271, 29489-29496.

Blagitko, N., Mergenthaler, S., Schulz, U., Wollmann, H. A., Craigen, W., Eggermann, T., Ropers, H. H., and Kalscheuer, V. M. (2000). Human GRB10 is imprinted and expressed from the paternal and maternal allele in a highly tissue- and isoformspecific fashion. Hum. Mol. Genet. 9, 1587-1595.

Blakesley, V. A., Kalebic, T., Helman, L. J., Stannard, B., Faria, T. N., Roberts, C. T. Jr., and LeRoith, D. (1996). Tumorigenic and mitogenic capacities are reduced in transfected fibroblasts expressing mutant insulin-like growth factor (IGF)I receptors. The role of tyrosine residues 1250, 1251, and 1316 in the carboxy-terminus of the IGF-I receptor. Endocrinology 137, 410-417.

Blakesley, V. A., Koval, A. P., Stannard, B. S., Scrimgeour, A., and LeRoith, D. (1998). Replacement of tyrosine 1251 in the carboxyl terminus of the insulin-like growth factor-I receptor disrupts the actin cytoskeleton and inhibits proliferation and anchorage-independent growth. J. Biol. Chem. 273, 18411-18422.

Bochukova, E. G., Huang, N., Keogh, J., Henning, E., Purmann, C., Blaszczyk, K., Saeed, S., HamiltonShield, J., Clayton-Smith, J., O’Rahilly, S., Hurles, M. E., and Farooqi, I. S. (2010). Large, rare chromosomal deletions associated with severe early-onset obesity. Nature 463, 666-670.

Boney, C. M., Gruppuso, P. A., Faris, R. A., and Frackelton, A. R. Jr. (2000). The critical role of Shc in insulin-like growth factor-I- mediated mitogenesis and differentiation in 3T3-L1 preadipocytes. Mol. Endocrinol. 14, 805-813.

Boney, C. M., Sekimoto, H., Gruppuso, P. A., and Frackelton, A. R. Jr. (2001) Src family tyrosine kinases participate in insulin-like growth factor I mitogenic signaling in 3T3-L1 cells. Cell Growth Differ. 12, 379-386.

Booth, R. A., Cummings, C., Tiberi, M., and Liu, X. J. (2002). GIPC participates in $G$ protein signaling downstream of insulin-like growth factor 1 receptor. J. Biol. Chem. 277, 6719-6725.

Boucher, J., Macotela, Y., Bezy, O., Mori, M. A., Kriauciunas, K., and Kahn, C. R. (2010a). A kinase-independent role for unoccupied insulin and IGF1 receptors in the control of apoptosis. Sci. Signal. 3, ra87.

Boucher, J., Tseng, Y. H., and Kahn, C. R. (2010b). Insulin and insulinlike growth factor- 1 receptors act as ligand-specific amplitude modulators of a common pathway regulating gene transcription. J. Biol. Chem. 285, 17235-17245.

Boura-Halfon, S., and Zick, Y. (2009). Phosphorylation of IRS proteins, insulin action, and insulin resistance. Am. J. Physiol. Endocrinol. Metab. 296, E581-E591.

Bouzakri, K., Zachrisson, A., Al-Khalili, L., Zhang, B. B., Koistinen, H. A., Krook, A., and Zierath, J. R. (2006). siRNA-based gene silencing reveals specialized roles of IRS-1/Akt2 and IRS-2/Akt1 in glucose and lipid metabolism in human skeletal muscle. Cell Metab. 4, 89-96.

Boykevisch, S., Zhao, C., Sondermann, H., Philippidou, P., Halegoua, S., Kuriyan, J., and Bar-Sagi, D. (2006). Regulation of ras signaling dynamics by Sos-mediated positive feedback. Curr. Biol. 16, 2173-2179.

Brannmark, C., Palmer, R., Glad, S. T., Cedersund, G., and Stralfors, P. (2010). Mass and information feedbacks through receptor endocytosis govern insulin signaling as revealed using a parameter-free modeling framework. J. Biol. Chem. 285, 20171-20179.

Bromann, P. A., Korkaya, H., and Courtneidge, S. A. (2004). The interplay between Src family kinases and receptor tyrosine kinases. Oncogene 23, 7957-7968.

Butler, A. A., and LeRoith, D. (2001). Minireview: tissue-specific versus generalized gene targeting of the igfl and igflr genes and their roles in insulin-like growth factor physiology. Endocrinology 142, 1685-1688. Cai, D., Dhe-Paganon, S., Melendez, P. A., Lee, J., and Shoelson, S. E. (2003). 
Two new substrates in insulin signaling, IRS5/DOK4 and IRS6/DOK5. J. Biol. Chem. 278, 25323-25330.

Cao, X. R., Lill, N. L., Boase, N., Shi, P. P., Croucher, D. R., Shan, H., Qu, J., Sweezer, E. M., Place, T., Kirby, P. A., Daly, R. J., Kumar, S., and Yang, B. (2008). Nedd4 controls animal growth by regulating IGF-1 signaling. Sci. Signal. 1, ra5.

Carre, N., Cauzac, M., Girard, J., and Burnol, A. F. (2008). Dual effect of the adapter growth factor receptorbound protein 14 (grb14) on insulin action in primary hepatocytes. Endocrinology 149, 3109-3117.

Carvalheira, J. B., Ribeiro, E. B., Folli, F., Velloso, L. A., and Saad, M. J. (2003). Interaction between leptin and insulin signaling pathways differentially affects JAK-STAT and PI 3-kinase-mediated signaling in rat liver. Biol. Chem. 384, 151-159.

Cedersund, G., Roll, J., Ulfhielm, E., Danielsson, A., Tidefelt, H., and Stralfors, P. (2008). Modelbased hypothesis testing of key mechanisms in initial phase of insulin signaling. PLoS Comput. Biol. 4, e1000096. doi:10.1371/journal.pcbi. 1000096

Ceresa, B. P., Kao, A. W., Santeler, S. R., and Pessin, J. E. (1998). Inhibition of clathrin-mediated endocytosis selectively attenuates specific insulin receptor signal transduction pathways. Mol. Cell. Biol. 18, 3862-3870.

Chang, L., Chiang, S. H., and Saltiel, A. R. (2004). Insulin signaling and the regulation of glucose transport. Mol. Med. 10, 65-71.

Charalambous, M., Cowley, M., Geoghegan, F., Smith, F. M., Radford, E. J., Marlow, B. P., Graham, C. F., Hurst, L. D., and Ward, A. (2010). Maternally-inherited Grb10 reduces placental size and efficiency. Dev. Biol. 337, 1-8.

Charalambous, M., Smith, F. M., Bennett, W. R., Crew, T. E., Mackenzie, F., and Ward, A. (2003). Disruption of the imprinted Grb10 gene leads to disproportionate overgrowth by an Igf2-independent mechanism. Proc. Natl. Acad. Sci. U.S.A. 100, 8292-8297.

Chen, J., Sadowski, H. B., Kohanski, R. A., and Wang, L. H. (1997). Stat5 is a physiological substrate of the insulin receptor. Proc. Natl. Acad. Sci. U.S.A. 94, 2295-2300.

Chen, J., Wu, A., Sun, H., Drakas, R., Garofalo, C., Cascio, S., Surmacz, E., and Baserga, R. (2005). Functional significance of type 1 insulinlike growth factor-mediated nuclear translocation of the insulin receptor substrate-1 and beta-catenin. J. Biol. Chem. 280, 29912-29920.

Choi, J. S., Paek, A. R., Kim, S. Y., and You, H. J. (2010). GIPC mediates the generation of reactive oxygen species and the regulation of cancer cell proliferation by insulin-like growth factor-1/IGF-1R signaling. Cancer Lett. 294, 254-263.

Chow, J. C., Condorelli, G., and Smith, R. J. (1998). Insulin-like growth factor-I receptor internalization regulates signaling via the Shc/mitogen-activated protein kinase pathway, but not the insulin receptor substrate-1 pathway. J. Biol. Chem. 273, 4672-4680.

Clark, S. F., Molero, J. C., and James, D. E. (2000). Release of insulin receptor substrate proteins from an intracellular complex coincides with the development of insulin resistance. $J$. Biol. Chem. 275, 3819-3826.

Clemmons, D. R., and Maile, L. A. (2003). Minireview: Integral membrane proteins that function coordinately with the insulin-like growth factor I receptor to regulate intracellular signaling. Endocrinology 144, 1664-1670.

Clemmons, D. R., and Maile, L. A. (2005). Interaction between insulinlike growth factor-I receptor and alphaVbeta3 integrin linked signaling pathways: cellular responses to changes in multiple signaling inputs. Mol. Endocrinol. 19, 1-11.

Clemmons, D. R., Maile, L. A., Ling, Y., Yarber, J., and Busby, W. H. (2007). Role of the integrin alphaVbeta3 in mediating increased smooth muscle cell responsiveness to IGFI in response to hyperglycemic stress. Growth Horm. IGF Res. 17, 265-270.

Coghlan, M. P., Pillay, T. S., Tavare, J. M., and Siddle, K. (1994). Sitespecific anti-phosphopeptide antibodies: use in assessing insulin receptor serine/threonine phosphorylation state and identification of serine-1327 as a novel site of phorbol ester-induced phosphorylation. Biochem. J. 303, 893-899.

Cohen, P. (2006). The twentieth century struggle to decipher insulin signalling. Nat. Rev. Mol. Cell Biol. 7, 867-873.

Cooney, G. J., Lyons, R. J., Crew, A. J., Jensen, T. E., Molero, J. C., Mitchell, C. J., Biden, T. J., Ormandy, C. J., James, D. E., and Daly, R. J. (2004). Improved glucose homeostasis and enhanced insulin signalling in Grb14-deficient mice. EMBO J. 23, 582-593.

Copeland, R. J., Bullen, J. W., and Hart, G. W. (2008). Cross-talk between
GlcNAcylation and phosphorylation: roles in insulin resistance and glucose toxicity. Am. J. Physiol. Endocrinol. Metab. 295, E17-E28.

Criswell, T., Beman, M., Araki, S. Leskov, K., Cataldo, E., Mayo, L. D., and Boothman, D. A. (2005). Delayed activation of insulin-like growth factor-1 receptor/Src/MAPK/Egr-1 signaling regulates clusterin expression, a pro-survival factor. J. Biol. Chem. 280, 14212-14221.

Da Silva Xavier, G., Qian, Q., Cullen, P. J., and Rutter, G. A. (2004). Distinct roles for insulin and insulinlike growth factor-1 receptors in pancreatic beta-cell glucose sensing revealed by RNA silencing. Biochem. J. 377, 149-158.

Dalle, S., Ricketts, W., Imamura, T., Vollenweider, P., and Olefsky, J. M. (2001). Insulin and insulinlike growth factor I receptors utilize different $G$ protein signaling components. J. Biol. Chem. 276, 15688-15695.

Dance, M., Montagner, A., Salles, J. P., Yart, A., and Raynal, P. (2008). The molecular functions of Shp2 in the Ras/mitogen-activated protein kinase (ERK1/2) pathway. Cell. Signal. 20, 453-459.

De Meyts, P. (2008). The insulin receptor: a prototype for dimeric allosteric membrane receptors? Trends Biochem. Sci. 33, 376-384.

De Meyts, P., and Whittaker, J. (2002). Structural biology of insulin and IGF1 receptors: implications for drug design. Nat. Rev. Drug Discov. 1, 769-783.

DeAngelis, A. M., Heinrich, G., Dai, T., Bowman, T. A., Patel, P. R., Lee, S. J., Hong, E. G., Jung, D. Y., Assmann, A., Kulkarni, R. N., Kim, J. K., and Najjar, S. M. (2008). Carcinoembryonic antigen-related cell adhesion molecule 1: a link between insulin and lipid metabolism. Diabetes 57 2296-2303.

Del Rosario, A. M., and White, F. M. (2010). Quantifying oncogenic phosphotyrosine signaling networks through systems biology. Curr. Opin. Genet. Dev. 20, 23-30

Depetris, R. S., Hu, J., Gimpelevich, I., Holt, L. J., Daly, R. J., and Hubbard, S. R. (2005). Structural basis for inhibition of the insulin receptor by the adaptor protein Grb14. Mol. Cell 20 325-333.

Depetris, R. S., Wu, J., and Hubbard, S. R. (2009). Structural and functional studies of the Ras-associating and pleckstrin-homology domains of Grb10 and Grb14. Nat. Struct. Mol. Biol. 16, 833-839.
DeWire, S. M., Ahn, S., Lefkowitz, R. J., and Shenoy, S. K. (2007). Betaarrestins and cell signaling. Annu. Rev. Physiol. 69, 483-510.

Di Cola, G., Cool, M. H., and Accili, D. (1997). Hypoglycemic effect of insulin-like growth factor-1 in mice lacking insulin receptors. J. Clin. Invest. 99, 2538-2544.

Di Guglielmo, G. M., Drake, P. G., Baass, P. C., Authier, F., Posner, B. I., and Bergeron, J. J. (1998). Insulin receptor internalization and signalling. Mol. Cell. Biochem. 182, 59-63.

Dozio, N., Scavini, M., Beretta, A., Sartori, S., Meschi, F., Sarugeri, E., and Pozza, G. (1995). In vivo metabolic effects of insulin-like growth factorI not mediated through the insulin receptor. J. Clin. Endocrinol. Metab. 80, 1325-1328.

Droge, W. (2005). Oxidative enhancement of insulin receptor signaling: experimental findings and clinical implications. Antioxid. Redox Signal. 7, 1071-1077.

Duan, C., Yang, H., White, M. F., and Rui, L. (2004). Disruption of the SH2-B gene causes agedependent insulin resistance and glucose intolerance. Mol. Cell. Biol. 24, 7435-7443.

Dube, N., and Tremblay, M. L. (2005). Involvement of the small protein tyrosine phosphatases TC-PTP and PTP1B in signal transduction and diseases: from diabetes, obesity to cell cycle, and cancer. Biochim. Biophys. Acta 1754, 108-117.

Dumont, J. E., Dremier, S., Pirson, I., and Maenhaut, C. (2002). Cross signaling, cell specificity, and physiology. Am. J. Physiol. Cell Physiol. 283 , C2-C28.

Dumont, J. E., Pecasse, F., and Maenhaut, C. (2001). Crosstalk and specificity in signalling. Are we crosstalking ourselves into general confusion? Cell Signal. 13, 457-463.

Dupont, J., Khan, J., Qu, B. H., Metzler, P., Helman, L., and LeRoith, D. (2001). Insulin and IGF-1 induce different patterns of gene expression in mouse fibroblast NIH3T3 cells: identification by cDNA microarray analysis. Endocrinology 142, 4969-4975.

Dupont, J., and LeRoith, D. (2001). Insulin and insulin-like growth factor I receptors: similarities and differences in signal transduction. Horm. Res. 55(Suppl. 2), 22-26.

Eck, M. J., Dhe-Paganon, S., Trub, T., Nolte, R. T., and Shoelson, S. E. (1996). Structure of the IRS-1 PTB domain bound to the juxtamembrane region of the insulin receptor. Cell 85, 695-705. 
Entingh-Pearsall, A., and Kahn, C. R. (2004). Differential roles of the insulin and insulin-like growth factor-I (IGF-I) receptors in response to insulin and IGF-I. $J$. Biol. Chem. 279, 38016-38024.

Esposito, D. L., Blakesley, V. A., Koval, A. P., Scrimgeour, A. G., and LeRoith, D. (1997). Tyrosine residues in the C-terminal domain of the insulinlike growth factor-I receptor mediate mitogenic and tumorigenic signals. Endocrinology 138, 2979-2988.

Falasca, M., Hughes, W. E., Dominguez, V., Sala, G., Fostira, F., Fang, M. Q., Cazzolli, R., Shepherd, P. R., James, D. E., and Maffucci, T. (2007). The role of phosphoinositide 3-kinase C2alpha in insulin signaling. J. Biol. Chem. 282, 28226-28236.

Falasca, M., and Maffucci, T. (2009). Rethinking phosphatidylinositol 3monophosphate. Biochim. Biophys. Acta 1793, 1795-1803.

Farese, R. V., and Sajan, M. P. (2010). Metabolic functions of atypical protein kinase C: "good" and "bad" as defined by nutritional status. Am . J. Physiol. Endocrinol. Metab. 298, E385-E394.

Farooq, A., Plotnikova, O., Zeng, L., and Zhou, M. M. (1999). Phosphotyrosine binding domains of Shc and insulin receptor substrate 1 recognize the NPXpY motif in a thermodynamically distinct manner. J. Biol. Chem. 274, 6114-6121.

Favelyukis, S., Till, J. H., Hubbard, S. R., and Miller, W. T. (2001). Structure and autoregulation of the insulinlike growth factor 1 receptor kinase. Nat. Struct. Biol. 8, 1058-1063.

Feller, S. M. (2001). Crk family adaptors-signalling complex formation and biological roles. Oncogene 20, 6348-6371.

Forbes, K., West, G., Garside, R., Aplin, J. D., and Westwood, M. (2009). The protein-tyrosine phosphatase, SRC homology-2 domain containing protein tyrosine phosphatase-2, is a crucial mediator of exogenous insulin-like growth factor signaling to human trophoblast. Endocrinology 150, 4744-4754.

Foti, M., Moukil, M. A., Dudognon, P., and Carpentier, J. L. (2004). Insulin and IGF-1 receptor trafficking and signalling. Novartis Found. Symp. 262, 125-141; discussion 141-127, 265-128.

Frasca, F., Pandini, G., Malaguarnera, R., Mandarino, A., Messina, R. L., Sciacca, L., Belfiore, A., and Vigneri, R. (2007). Role of c-Abl in directing metabolic versus mitogenic effects in insulin receptor signaling. J. Biol. Chem. 282, 26077-26088.
Frasca, F., Pandini, G., Scalia, P., Sciacca, L., Mineo, R., Costantino, A., Goldfine, I. D., Belfiore, A., and Vigneri, R. (1999). Insulin receptor isoform $\mathrm{A}$, a newly recognized, highaffinity insulin-like growth factor II receptor in fetal and cancer cells. Mol. Cell. Biol. 19, 3278-3288.

Fritsche, L., Neukamm, S. S., Lehmann, R., Kremmer, E., Hennige, A. M., Hunder-Gugel, A., Schenk, M., Haring, H. U., Schleicher, E. D., and Weigert, C. (2011). Insulin-induced serine phosphorylation of IRS-2 via ERK1/2 and mTOR: studies on the function of Ser675 and Ser907. Am. J. Physiol. Endocrinol. Metab. 300 E824-E836.

Fukunaga, K., Noguchi, T., Takeda, H., Matozaki, T., Hayashi, Y., Itoh, H., and Kasuga, M. (2000). Requirement for protein-tyrosine phosphatase SHP-2 in insulin-induced activation of c-Jun $\mathrm{NH}(2)$-terminal kinase. $J$. Biol. Chem. 275, 5208-5213.

Furlanetto, R. W., Dey, B. R., Lopaczynski, W., and Nissley, S. P. (1997). 14-3-3 proteins interact with the insulin-like growth factor receptor but not the insulin receptor. Biochem. J. 327, 765-771.

Fuss, B., Becker, T., Zinke, I., and Hoch, M. (2006). The cytohesin Steppke is essential for insulin signalling in Drosophila. Nature 444, 945-948.

Garfield, A. S., Cowley, M., Smith, F. M., Moorwood, K., Stewart-Cox, J. E., Gilroy, K., Baker, S., Xia, J., Dalley, J. W., Hurst, L. D., Wilkinson, L. S., Isles, A. R., and Ward, A. (2011). Distinct physiological and behavioural functions for parental alleles of imprinted Grb10. Nature 469, 534-538.

Genua, M., Pandini, G., Cassarino, M. F., Messina, R. L., and Frasca, F. (2009). c-Abl and insulin receptor signalling. Vitam. Horm. 80, $77-105$.

Giorgetti-Peraldi, S., Peyrade, F., Baron, V., and Van Obberghen, E. (1995). Involvement of Janus kinases in the insulin signaling pathway. Eur. $J$. Biochem. 234, 656-660.

Girnita, L., Girnita, A., and Larsson, O. (2003). Mdm2-dependent ubiquitination and degradation of the insulin-like growth factor 1 receptor. Proc. Natl. Acad. Sci. U.S.A. 100, 8247-8252.

Girnita, L., Shenoy, S. K., Sehat, B., Vasilcanu, R., Girnita, A., Lefkowitz, R. J., and Larsson, O. (2005). \{beta $\}$ Arrestin is crucial for ubiquitination and down-regulation of the insulinlike growth factor-1 receptor by acting as adaptor for the MDM2 E3 ligase. J. Biol. Chem. 280, 24412-24419.
Girnita, L., Shenoy, S. K., Sehat, B. Vasilcanu, R., Vasilcanu, D., Girnita, A., Lefkowitz, R. J., and Larsson, O. (2007). Beta-arrestin and $\mathrm{Mdm} 2$ mediate IGF-1 receptorstimulated ERK activation and cell cycle progression. J. Biol. Chem. 282, 11329-11338.

Giudice, J., Leskow, F. C., Arndt-Jovin, D. J., Jovin, T. M., and Jares-Erijman, E. A. (2011). Differential endocytosis and signaling dynamics of insulin receptor variants IR-A and IR-B. J. Cell. Sci. 124, 801-811.

Goel, H. L., Breen, M., Zhang, J., Das, I., Aznavoorian-Cheshire, S., Greenberg, N. M., Elgavish, A., and Languino, L. R. (2005). betalA integrin expression is required for type 1 insulin-like growth factor receptor mitogenic and transforming activities and localization to focal contacts. Cancer Res. 65, 6692-6700.

Goel, H. L., Fornaro, M., Moro, L. Teider, N., Rhim, J. S., King, M. and Languino, L. R. (2004). Selective modulation of type 1 insulinlike growth factor receptor signaling and functions by betal integrins. $J$. Cell Biol. 166, 407-418.

Goenaga, D., Hampe, C., Carre, N., Cailliau, K., Browaeys-Poly, E. Perdereau, D., Holt, L. J., Daly, R. J., Girard, J., Broutin, I., Issad, T., and Burnol, A. F. (2009). Molecular determinants of Grb14-mediated inhibition of insulin signaling. Mol. Endocrinol. 23, 1043-1051.

Goh, E. L., Zhu, T., Yakar, S., LeRoith, D., and Lobie, P. E. (2000). CrkII participation in the cellular effects of growth hormone and insulin-like growth factor-1. Phosphatidylinositol-3 kinase dependent and independent effects. J. Biol. Chem. 275, 17683-17692.

Goldfine, I. D., Maddux, B. A., Youngren, J. F., Reaven, G., Accili, D., Trischitta, V., Vigneri, R., and Frittitta, L. (2008). The role of membrane glycoprotein plasma cell antigen 1/ectonucleotide pyrophosphatase phosphodiesterase 1 in the pathogenesis of insulin resistance and related abnormalities. Endocr. Rev. 29, 62-75.

Goldfine, I. D., Purrello, F., Clawson, G. A., and Vigneri, R. (1982). Insulin binding sites on the nuclear envelope: potential relationship to mRNA metabolism. J. Cell. Biochem. 20, 29-39.

Goldstein, B. J., Mahadev, K., Wu, X., Zhu, L., and Motoshima, H. (2005). Role of insulin-induced reactive oxygen species in the insulin signaling pathway. Antioxid. Redox Signal. 7, 1021-1031.
Gotoh, N. (2008). Regulation of growth factor signaling by FRS2 family docking/scaffold adaptor proteins. Cancer Sci. 99, 1319-1325.

Gotoh, N., Toyoda, M., and Shibuya, M. (1997). Tyrosine phosphorylation sites at amino acids 239 and 240 of Shc are involved in epidermal growth factor-induced mitogenic signaling that is distinct from Ras/mitogen-activated protein kinase activation. Mol. Cell. Biol. 17, 1824-1831.

Gual, P., Baron, V., Lequoy, V., and Van Obberghen, E. (1998). Interaction of Janus kinases JAK-1 and JAK-2 with the insulin receptor and the insulin-like growth factor-1 receptor. Endocrinology 139, 884-893.

Gureasko, J., Galush, W. J., Boykevisch, S., Sondermann, H., Bar-Sagi, D. Groves, J. T., and Kuriyan, J. (2008). Membrane-dependent signal integration by the Ras activator Son of sevenless. Nat. Struct. Mol. Biol. 15 , 452-461.

Hafner, M., Schmitz, A., Grune, I., Srivatsan, S. G., Paul, B., Kolanus, W., Quast, T., Kremmer, E., Bauer, I., and Famulok, M. (2006). Inhibition of cytohesins by SecinH3 leads to hepatic insulin resistance. Nature 444, 941-944.

Haft, C. R., De La Luz Sierra, M., Hamer, I., Carpentier, J. L., and Taylor, S. I. (1998). Analysis of the juxtamembrane dileucine motif in the insulin receptor. Endocrinology 139, 1618-1629.

Hamer, I., Foti, M., Emkey, R., CordierBussat, M., Philippe, J., De Meyts, P., Maeder, C., Kahn, C. R., and Carpentier, J. L. (2002). An arginine to cysteine (252) mutation in insulin receptors from a patient with severe insulin resistance inhibits receptor internalisation but preserves signalling events. Diabetologia 45, 657-667.

Hanke, S., and Mann, M. (2009). The phosphotyrosine interactome of the insulin receptor family and its substrates IRS-1 and IRS-2. Mol. Cell Proteomics 8, 519-534.

Hansen, B. F., Danielsen, G. M., Drejer, K., Sorensen, A. R., Wiberg, F. C., Klein, H. H., and Lundemose, A. G. (1996). Sustained signalling from the insulin receptor after stimulation with insulin analogues exhibiting increased mitogenic potency. Biochem. J. 315, 271-279.

Harada, S., Esch, G. L., HolgadoMadruga, M., and Wong, A. J. (2001). Grb-2-associated binder1 is involved in insulin-induced egr-1 gene expression through its phosphatidylinositol $3^{\prime}$-kinase 
binding site. DNA Cell Biol. 20, 223-229.

Hayashi, K., Shibata, K., Morita, T., Iwasaki, K., Watanabe, M., and Sobue, K. (2004). Insulin receptor substrate-1/SHP-2 interaction, a phenotype-dependent switching machinery of insulin-like growth factor-I signaling in vascular smooth muscle cells. J. Biol. Chem. 279, 40807-40818.

Hermanto, U., Zong, C. S., Li, W., and Wang, L. H. (2002). RACK1, an insulin-like growth factor I (IGF-I) receptor-interacting protein, modulates IGF-I-dependent integrin signaling and promotes cell spreading and contact with extracellular matrix. Mol. Cell. Biol. 22, 2345-2365.

Himpe, E., and Kooijman, R. (2009). Insulin-like growth factor-I receptor signal transduction and the Janus Kinase/Signal Transducer and Activator of Transcription (JAK-STAT) pathway. Biofactors 35, 76-81.

Hoehn, K. L., Hohnen-Behrens, C., Cederberg, A., Wu, L. E., Turner, N., Yuasa, T., Ebina, Y., and James, D. E. (2008). IRS1-independent defects define major nodes of insulin resistance. Cell Metab. 7, 421-433.

Hof, P., Pluskey, S., Dhe-Paganon, S., Eck, M. J., and Shoelson, S. E. (1998). Crystal structure of the tyrosine phosphatase SHP-2. Cell 92, 441-450.

Holgado-Madruga, M., Emlet, D. R., Moscatello, D. K., Godwin, A. K., and Wong, A. J. (1996). A Grb2-associated docking protein in EGF- and insulin-receptor signalling. Nature 379, 560-564.

Holt, L. J., Lyons, R. J., Ryan, A. S., Beale, S. M., Ward, A., Cooney, G. J., and Daly, R. J. (2009). Dual ablation of Grb10 and Grb14 in mice reveals their combined role in regulation of insulin signaling and glucose homeostasis. Mol. Endocrinol. 23, 1406-1414.

Holt, L. J., and Siddle, K. (2005). Grb10 and Grb14: enigmatic regulators of insulin action - and more? Biochem. J. 388, 393-406.

Hosooka, T., Noguchi, T., Kotani, K., Nakamura, T., Sakaue, H., Inoue, H., Ogawa, W., Tobimatsu, K., Takazawa, K., Sakai, M., Matsuki, Y., Hiramatsu, R., Yasuda, T., Lazar, M. A., Yamanashi, Y., and Kasuga, M. (2008). Dok1 mediates highfat diet-induced adipocyte hypertrophy and obesity through modulation of PPAR-gamma phosphorylation. Nat. Med. 14, 188-193.

Howard, J. K., and Flier, J. S. (2006). Attenuation of leptin and insulin signaling by SOCS proteins. Trends Endocrinol. Metab. 17, 365-371.

Hsu, M. F., and Meng, T. C. (2010). Enhancement of insulin responsiveness by nitric oxide-mediated inactivation of protein-tyrosine phosphatases. J. Biol. Chem. 285, 7919-7928.

Hsu, P. P., Kang, S. A., Rameseder, J., Zhang, Y., Ottina, K. A., Lim, D., Peterson, T. R., Choi, Y., Gray, N. S., Yaffe, M. B., Marto, J. A., and Sabatini, D. M. (2011). The mTORregulated phosphoproteome reveals a mechanism of mTORC1-mediated inhibition of growth factor signaling. Science 332, 1317-1322.

$\mathrm{Hu}$, J., and Hubbard, S. R. (2005). Structural characterization of a novel $\mathrm{Cbl}$ phosphotyrosine recognition motif in the APS family of adapter proteins. J. Biol. Chem. 280, 18943-18949.

Hu, J., and Hubbard, S. R. (2006). Structural basis for phosphotyrosine recognition by the Src homology2 domains of the adapter proteins SH2-B and APS. J. Mol. Biol. 361, 69-79.

Hu, J., Liu, J., Ghirlando, R., Saltiel, A. R., and Hubbard, S. R. (2003). Structural basis for recruitment of the adaptor protein APS to the activated insulin receptor. Mol. Cell 12, 1379-1389.

Huang, C., Thirone, A. C., Huang, X., and Klip, A. (2005). Differential contribution of insulin receptor substrates 1 versus 2 to insulin signaling and glucose uptake in 16 myotubes. J. Biol. Chem. 280, 19426-19435.

Huang, Q., and Szebenyi, D. M. (2010). Structural basis for the interaction between the growth factor-binding protein GRB10 and the E3 ubiquitin ligase NEDD4. J. Biol. Chem. 285, 42130-42139.

Huang, S. M., Hancock, M. K., Pitman, J. L., Orth, A. P., and Gekakis, N. (2009). Negative regulators of insulin signaling revealed in a genome-wide functional screen. PLoS ONE 4, e6871. doi:10.1371/journal.pone.0006871

Hubbard, S. R. (1997). Crystal structure of the activated insulin receptor tyrosine kinase in complex with peptide substrate and ATP analog. EMBO J. 16, 5572-5581.

Hupfeld, C. J., and Olefsky, J. M. (2007). Regulation of receptor tyrosine kinase signaling by GRKs and beta-arrestins. Annu. Rev. Physiol. 69, 561-577.

Ikeda, F., and Dikic, I. (2008). Atypical ubiquitin chains: new molecular signals. 'Protein Modifications:
Beyond the Usual Suspects' review series. EMBO Rep. 9, 536-542.

Imamura, T., Vollenweider, P., Egawa, K., Clodi, M., Ishibashi, K., Nakashima, N., Ugi, S., Adams, J. W., Brown J. H., and Olefsky, J. M. (1999). G alpha-q/11 protein plays a key role in insulin-induced glucose transport in 3T3-L1 adipocytes. Mol. Cell. Biol. 19, 6765-6774.

Inoue, G., Cheatham, B., Emkey, R., and Kahn, C. R. (1998). Dynamics of insulin signaling in 3T3L1 adipocytes. Differential compartmentalization and trafficking of insulin receptor substrate (IRS)1 and IRS-2. J. Biol. Chem. 273 , 11548-11555.

Inoue, M., Chiang, S. H., Chang, L. Chen, X. W., and Saltiel, A. R. (2006). Compartmentalization of the exocyst complex in lipid rafts controls Glut4 vesicle tethering. Mol. Biol. Cell 17, 2303-2311.

Ish-Shalom, D., Christoffersen, C. T., Vorwerk, P., Sacerdoti-Sierra, N., Shymko, R. M., Naor, D., and De Meyts, P. (1997). Mitogenic properties of insulin and insulin analogues mediated by the insulin receptor. Diabetologia 40(Suppl. 2), S25-S31.

Janssen-Heininger, Y. M., Mossman, B. T., Heintz, N. H., Forman, H. J., Kalyanaraman, B., Finkel, T., Stamler, J. S., Rhee, S. G., and Van Der Vliet, A. (2008). Redox-based regulation of signal transduction: principles, pitfalls, and promises. Free Radic. Biol. Med. 45, 1-17.

JeBailey, L., Rudich, A., Huang, X., Di Ciano-Oliveira, C., Kapus, A. and Klip, A. (2004). Skeletal muscle cells and adipocytes differ in their reliance on TC10 and Rac for insulin-induced actin remodeling. Mol. Endocrinol. 18, 359-372.

Jensen, M., and De Meyts, P. (2009). Molecular mechanisms of differential intracellular signaling from the insulin receptor. Vitam. Horm. 80 51-75.

Jensen, M., Palsgaard, J., Borup, R., De Meyts, P., and Schaffer, L. (2008). Activation of the insulin receptor (IR) by insulin and a synthetic peptide has different effects on gene expression in IR-transfected L6 myoblasts. Biochem. J. 412, 435-445.

Jin, S., Zhai, B., Qiu, Z., Wu, J., Lane, M. D., and Liao, K. (2000). c-Crk, a substrate of the insulin-like growth factor-1 receptor tyrosine kinase, functions as an early signal mediator in the adipocyte differentiation process. J. Biol. Chem. 275, 34344-34352.

Kanzaki, M., Mora, S., Hwang, J. B., Saltiel, A. R., and Pessin, J. E.
(2004). Atypical protein kinase C (PKCzeta/lambda) is a convergent downstream target of the insulinstimulated phosphatidylinositol 3kinase and TC10 signaling pathways. J. Cell Biol. 164, 279-290.

Kanzaki, M., Watson, R. T., Hou, J. C., Stamnes, M., Saltiel, A. R., and Pessin, J. E. (2002). Small GTP-binding protein TC10 differentially regulates two distinct populations of filamentous actin in 3T3L1 adipocytes. Mol. Biol. Cell 13, 2334-2346.

Katsanakis, K. D., and Pillay, T. S. (2005). Cross-talk between the two divergent insulin signaling pathways is revealed by the protein kinase $B$ (Akt)-mediated phosphorylation of adapter protein APS on serine 588. J. Biol. Chem. 280, 37827-37832.

Kaushansky, A., Gordus, A., Chang, B. Rush, J., and Macbeath, G. (2008). A quantitative study of the recruitment potential of all intracellular tyrosine residues on EGFR, FGFR1 and IGF1R. Mol. Biosyst. 4, 643-653.

Kellerer, M., and Haring, H. U. (1995). Pathogenesis of insulin resistance: modulation of the insulin signal at receptor level. Diabetes Res. Clin. Pract. 28(Suppl.), S173-S177.

Kellerer, M., Lammers, R., Ermel, B., Tippmer, S., Vogt, B., ObermaierKusser, B., Ullrich, A., and Haring, H. U. (1992). Distinct alpha-subunit structures of human insulin receptor $\mathrm{A}$ and $\mathrm{B}$ variants determine differences in tyrosine kinase activities. Biochemistry 31, 4588-4596.

Keyhanfar, M., Booker, G. W., Whittaker, J., Wallace, J. C., and Forbes, B. E. (2007). Precise mapping of an IGF-Ibinding site on the IGF-1R. Biochem. J. 401, 269-277.

Kiely, P. A., Baillie, G. S., Barrett, R., Buckley, D. A., Adams, D. R., Houslay, M. D., and O'Connor, R. (2009). Phosphorylation of RACK1 on tyrosine 52 by $\mathrm{c}-\mathrm{Abl}$ is required for insulin-like growth factor Imediated regulation of focal adhesion kinase. J. Biol. Chem. 284, 20263-20274.

Kiely, P. A., Baillie, G. S., Lynch, M. J., Houslay, M. D., and O'Connor, R. (2008). Tyrosine 302 in RACK1 is essential for insulin-like growth factor-I-mediated competitive binding of PP2A and betal integrin and for tumor cell proliferation and migration. J. Biol. Chem. 283, 22952-22961.

Kiely, P. A., Leahy, M., O'Gorman, D., and O'Connor, R. (2005). RACK1mediated integration of adhesion and insulin-like growth factor I (IGF-I) signaling and cell migration 
are defective in cells expressing an IGF-I receptor mutated at tyrosines 1250 and 1251. J. Biol. Chem. 280, 7624-7633.

Kiely, P. A., O'Gorman, D., Luong, K., Ron, D., and O'Connor, R. (2006). Insulin-like growth factor I controls a mutually exclusive association of RACK1 with protein phosphatase $2 \mathrm{~A}$ and betal integrin to promote cell migration. Mol. Cell. Biol. 26, 4041-4051.

Kiely, P. A., Sant, A., and O'Connor, R. (2002). RACK1 is an insulin-like growth factor 1 (IGF-1) receptorinteracting protein that can regulate IGF-1-mediated Akt activation and protection from cell death. J. Biol. Chem. 277, 22581-22589.

Kim, B., Cheng, H. L., Margolis, B., and Feldman, E. L. (1998). Insulin receptor substrate 2 and Shc play different roles in insulin-like growth factor I signaling. J. Biol. Chem. 273, 34543-34550.

Kim, J. J., and Accili, D. (2002). Signalling through IGF-I and insulin receptors: where is the specificity? Growth Horm. IGF Res. 12, 84-90.

King, C. C., and Newton, A. C. (2004). The adaptor protein Grb14 regulates the localization of 3-phosphoinositide-dependent kinase-1. J. Biol. Chem. 279, 37518-37527.

Kirkin, V., and Dikic, I. (2007). Role of ubiquitin- and Ubl-binding proteins in cell signaling. Curr. Opin. Cell Biol. 19, 199-205.

Kiselyov, V. V., Versteyhe, S., Gauguin, L., and De Meyts, P. (2009). Harmonic oscillator model of the insulin and IGF1 receptors' allosteric binding and activation. Mol. Syst. Biol. 5, 243.

Kishi, K., Mawatari, K., SakaiWakamatsu, K., Yuasa, T., Wang, M., Ogura-Sawa, M., Nakaya, Y., Hatakeyama, S., and Ebina, Y. (2007). APS-mediated ubiquitination of the insulin receptor enhances its internalization, but does not induce its degradation. Endocr. J. 54, 77-88.

Kitamura, T., Kahn, C. R., and Accili, D. (2003). Insulin receptor knockout mice. Annu. Rev. Physiol. 65, 313-332.

Klammt, J., Barnikol-Oettler, A., and Kiess, W. (2004). Mutational analysis of the interaction between insulin receptor and IGF-I receptor with cCrk and Crk-L in a yeast two-hybrid system. Biochem. Biophys. Res. Commun. 325, 183-190.

Klein, A. L., Berkaw, M. N., Buse, M. G., and Ball, L. E. (2009). O-linked $N$ acetylglucosamine modification of insulin receptor substrate-1 occurs in close proximity to multiple $\mathrm{SH} 2$ domain binding motifs. Mol. Cell Proteomics 8, 2733-2745.

Kolanus, W. (2007). Guanine nucleotide exchange factors of the cytohesin family and their roles in signal transduction. Immunol. Rev. 218, 102-113.

Kotani, K., Wilden, P., and Pillay, T. S. (1998). SH2-Balpha is an insulinreceptor adapter protein and substrate that interacts with the activation loop of the insulin-receptor kinase. Biochem. J. 335, 103-109.

Koval, A. P., Blakesley, V. A., Roberts, C. T. Jr., Zick, Y., and LeRoith, D. (1998a). Interaction in vitro of the product of the c-Crk-II protooncogene with the insulin-like growth factor I receptor. Biochem. J. 330, 923-932.

Koval, A. P., Karas, M., Zick, Y., and LeRoith, D. (1998b). Interplay of the proto-oncogene proteins CrkL and CrkII in insulin-like growth factor-I receptor-mediated signal transduction. J. Biol. Chem. 273, 14780-14787.

Kruger, M., Kratchmarova, I., Blagoev, B., Tseng, Y. H., Kahn, C. R., and Mann, M. (2008). Dissection of the insulin signaling pathway via quantitative phosphoproteomics. Proc. Natl. Acad. Sci. U.S.A. 105, 2451-2456.

Kulkarni, R. N. (2005). New insights into the roles of insulin/IGF-I in the development and maintenance of beta-cell mass. Rev. Endocr. Metab. Disord. 6, 199-210.

Kwon, M., Ling, Y., Maile, L. A., Badley-Clark, J., and Clemmons, D. R. (2006). Recruitment of the tyrosine phosphatase Src homology 2 domain tyrosine phosphatase- 2 to the p85 subunit of phosphatidylinositol-3 (PI-3) kinase is required for insulin-like growth factor-I-dependent PI-3 kinase activation in smooth muscle cells. Endocrinology 147, 1458-1465.

Lamb, C. A., Mccann, R. K., Stockli, J., James, D. E., and Bryant, N. J. (2010). Insulin-regulated trafficking of GLUT4 requires ubiquitination. Traffic 11, 1445-1454.

Lammers, R., Gray, A., Schlessinger, J., and Ullrich, A. (1989). Differential signalling potential of insulin- and IGF-1-receptor cytoplasmic domains. EMBO J. 8, 1369-1375.

Langlais, P., Dong, L. Q., Hu, D., and Liu, F. (2000). Identification of Grb10 as a direct substrate for members of the Src tyrosine kinase family. Oncogene 19, 2895-2903.
Laviola, L., Natalicchio, A., and Giorgino, F. (2007). The IGF-I signaling pathway. Curr. Pharm. Des. 13, 663-669.

Lawrence, M. C., Mckern, N. M., and Ward, C. W. (2007). Insulin receptor structure and its implications for the IGF-1 receptor. Curr. Opin. Struct. Biol. 17, 699-705.

Leahy, M., Lyons, A., Krause, D., and O'Connor, R. (2004). Impaired Shc, Ras, and MAPK activation but normal Akt activation in FL5.12 cells expressing an insulin-like growth factor I receptor mutated at tyrosines 1250 and 1251. J. Biol. Chem. 279, 18306-18313.

Lebrun, P., and Van Obberghen, E. (2008). SOCS proteins causing trouble in insulin action. Acta Physiol. (Oxf.) 192, 29-36.

Lefkowitz, R. J., and Shenoy, S. K. (2005). Transduction of receptor signals by beta-arrestins. Science 308, 512-517.

Lehr, S., Kotzka, J., Herkner, A., Sikmann, A., Meyer, H. E., Krone, W., and Muller-Wieland, D. (2000). Identification of major tyrosine phosphorylation sites in the human insulin receptor substrate Gab-1 by insulin receptor kinase in vitro. Biochemistry 39, 10898-10907.

Leibiger, B., Moede, T., Uhles, S., Barker, C. J., Creveaux, M., Domin, J., Berggren, P. O., and Leibiger, I. B. (2010a). Insulin-feedback via PI3KC2alpha activated PKBalpha/Aktl is required for glucose-stimulated insulin secretion. FASEB J. 24, 1824-1837.

Leibiger, I. B., Brismar, K., and Berggren, P. O. (2010b). Novel aspects on pancreatic beta-cell signal-transduction. Biochem. Biophys. Res. Commun. 396, 111-115.

Lemmon, M. A., and Schlessinger, J. (2010). Cell signaling by receptor tyrosine kinases. Cell 141, 1117-1134.

Li, M., Li, Z., Morris, D. L., and Rui, L. (2007). Identification of SH2B2beta as an inhibitor for SH2B1- and SH2B2alpha-promoted Janus kinase-2 activation and insulin signaling. Endocrinology 148, 1615-1621.

Li, M., Ren, D., Iseki, M., Takaki, S., and Rui, L. (2006). Differential role of SH2-B and APS in regulating energy and glucose homeostasis. Endocrinology 147, 2163-2170.

Li, S., Brown, M. S., and Goldstein, J. L. (2010). Bifurcation of insulin signaling pathway in rat liver: mTORC1 required for stimulation of lipogenesis, but not inhibition of gluconeogenesis. Proc. Natl. Acad. Sci. U.S.A. 107, 3441-3446.

Lieskovska, J., Ling, Y., Badley-Clarke, J., and Clemmons, D. R. (2006). The role of Src kinase in insulinlike growth factor-dependent mitogenic signaling in vascular smooth muscle cells. J. Biol. Chem. 281, 25041-25053.

Ligensa, T., Krauss, S., Demuth, D., Schumacher, R., Camonis, J., Jaques, G., and Weidner, K. M. (2001). A PDZ domain protein interacts with the C-terminal tail of the insulinlike growth factor-1 receptor but not with the insulin receptor. J. Biol. Chem. 276, 33419-33427.

Lim, J., Zhou, M., Veenstra, T. D., and Morrison, D. K. (2010). The CNK1 scaffold binds cytohesins and promotes insulin pathway signaling. Genes Dev. 24, 1496-1506.

Lim, M. A., Riedel, H., and Liu, F. (2004). Grb10: more than a simple adaptor protein. Front. Biosci. 9, 387-403.

Lin, F. T., Daaka, Y., and Lefkowitz, R. J. (1998). beta-arrestins regulate mitogenic signaling and clathrinmediated endocytosis of the insulinlike growth factor I receptor. J. Biol. Chem. 273, 31640-31643.

Liu, F., and Roth, R. A. (1994). Identification of serines-1035/1037 in the kinase domain of the insulin receptor as protein kinase $\mathrm{C}$ alpha mediated phosphorylation sites. FEBS Lett. 352, 389-392.

Liu, H., Kublaoui, B., Pilch, P. F., and Lee, J. (2000). Insulin activation of mitogen-activated protein (MAP) kinase and Akt is phosphatidylinositol 3-kinase-dependent in rat adipocytes. Biochem. Biophys. Res. Commun. 274, 845-851.

Liu, J., Kimura, A., Baumann, C. A., and Saltiel, A. R. (2002). APS facilitates c-Cbl tyrosine phosphorylation and GLUT4 translocation in response to insulin in 3T3-L1 adipocytes. Mol. Cell. Biol. 22, 3599-3609.

Lodhi, I. J., Bridges, D., Chiang, S. H., Zhang, Y., Cheng, A., Geletka, L. M., Weisman, L. S., and Saltiel, A. R. (2008). Insulin stimulates phosphatidylinositol 3-phosphate production via the activation of Rab5. Mol. Biol. Cell 19, 2718-2728.

Loh, K., Deng, H., Fukushima, A., Cai, X., Boivin, B., Galic, S., Bruce, C., Shields, B. J., Skiba, B., Ooms, L. M., Stepto, N., Wu, B., Mitchell, C. A., Tonks, N. K., Watt, M. J., Febbraio, M. A., Crack, P. J., Andrikopoulos, S., and Tiganis, T. (2009). Reactive oxygen species enhance insulin sensitivity. Cell Metab. 10, 260-272.

Louvi, A., Accili, D., and Efstratiadis, A. (1997). Growth-promoting 
interaction of IGF-II with the insulin receptor during mouse embryonic development. Dev. Biol. 189, 33-48.

Luan, B., Zhao, J., Wu, H., Duan, B., Shu, G., Wang, X., Li, D., Jia, W., Kang, J., and Pei, G. (2009). Deficiency of a beta-arrestin-2 signal complex contributes to insulin resistance. Nature 457, 1146-1149.

Lund, S., Flyvbjerg, A., Holman, G. D., Larsen, F. S., Pedersen, O., and Schmitz, O. (1994). Comparative effects of IGF-I and insulin on the glucose transporter system in rat muscle. Am. J. Physiol. 267, E461E466.

Luzi, L., Confalonieri, S., Di Fiore, P. P., and Pelicci, P. G. (2000). Evolution of Shc functions from nematode to human. Curr. Opin. Genet. Dev. 10, 668-674.

Mahadev, K., Motoshima, H., Wu, X., Ruddy, J. M., Arnold, R. S., Cheng, G., Lambeth, J. D., and Goldstein, B. J. (2004). The NAD(P)H oxidase homolog Nox4 modulates insulinstimulated generation of $\mathrm{H} 2 \mathrm{O} 2$ and plays an integral role in insulin signal transduction. Mol. Cell. Biol. 24, 1844-1854.

Maile, L. A., and Clemmons, D. R. (2002). Regulation of insulin-like growth factor I receptor dephosphorylation by SHPS-1 and the tyrosine phosphatase SHP-2. J. Biol. Chem. 277, 8955-8960.

Manning, B. D., and Cantley, L. C. (2007). AKT/PKB signaling: navigating downstream. Cell 129, 1261-1274.

Mashima, R., Hishida, Y., Tezuka, T., and Yamanashi, Y. (2009). The roles of Dok family adapters in immunoreceptor signaling. Immunol. Rev. 232, 273-285.

Maures, T. J., Kurzer, J. H., and Carter$\mathrm{Su}, \mathrm{C}$. (2007). SH2B1 (SH2-B) and JAK2: a multifunctional adaptor protein and kinase made for each other. Trends Endocrinol. Metab. 18, 38-45.

McCahill, A., Warwicker, J., Bolger, G. B., Houslay, M. D., and Yarwood, S. J. (2002). The RACK1 scaffold protein: a dynamic cog in cell response mechanisms. Mol. Pharmacol. 62, 1261-1273.

Meloche, S., and Pouyssegur, J. (2007). The ERK1/2 mitogen-activated protein kinase pathway as a master regulator of the G1- to S-phase transition. Oncogene 26, 3227-3239.

Meng, D., Lv, D. D., and Fang, J. (2008). Insulin-like growth factor-I induces reactive oxygen species production and cell migration through Nox4 and Racl in vascular smooth muscle cells. Cardiovasc. Res. 80, 299-308.
Miele, C., Rochford, J. J., Filippa, N., Giorgetti-Peraldi, S., and Van Obberghen, E. (2000). Insulin and insulin-like growth factor-I induce vascular endothelial growth factor mRNA expression via different signaling pathways. J. Biol. Chem. 275, 21695-21702.

Minami, A., Iseki, M., Kishi, K., Wang, M., Ogura, M., Furukawa, N., Hayashi, S., Yamada, M., Obata, T., Takeshita, Y., Nakaya, Y., Bando, Y., Izumi, K., Moodie, S. A., Kajiura, F., Matsumoto, M., Takatsu, K., Takaki, S., and Ebina, Y. (2003). Increased insulin sensitivity and hypoinsulinemia in APS knockout mice. Diabetes 52, 2657-2665.

Miura, M., and Baserga, R. (1997). The tyrosine residue at 1250 of the insulin-like growth factor I receptor is required for ligand-mediated internalization. Biochem. Biophys. Res. Commun. 239, 182-185.

Miura, M., Surmacz, E., Burgaud, J. L., and Baserga, R. (1995). Different effects on mitogenesis and transformation of a mutation at tyrosine 1251 of the insulin-like growth factor I receptor. J. Biol. Chem. 270, 22639-22644.

Molero, J. C., Jensen, T. E., Withers, P. C., Couzens, M., Herzog, H., Thien, C. B., Langdon, W. Y., Walder, K., Murphy, M. A., Bowtell, D. D., James, D. E., and Cooney, G. J. (2004). c-Cbldeficient mice have reduced adiposity, higher energy expenditure, and improved peripheral insulin action. J. Clin. Invest. 114, 1326-1333.

Molero, J. C., Turner, N., Thien, C. B., Langdon, W. Y., James, D. E., and Cooney, G. J. (2006a). Genetic ablation of the c-Cbl ubiquitin ligase domain results in increased energy expenditure and improved insulin action. Diabetes 55, 3411-3417.

Molero, J. C., Waring, S. G., Cooper, A., Turner, N., Laybutt, R., Cooney, G. J., and James, D. E. (2006b). Casitas b-lineage lymphoma-deficient mice are protected against high-fat dietinduced obesity and insulin resistance. Diabetes 55, 708-715.

Moodie, S. A., Alleman-Sposeto, J., and Gustafson, T. A. (1999). Identification of the APS protein as a novel insulin receptor substrate. J. Biol. Chem. 274, 11186-11193.

Morrione, A., Valentinis, B., Xu, S. Q., Yumet, G., Louvi, A., Efstratiadis, A., and Baserga, R. (1997). Insulin-like growth factor II stimulates cell proliferation through the insulin receptor. Proc. Natl. Acad. Sci. U.S.A. 94, 3777-3782.

Morris, D. L., Cho, K. W., and Rui, L. (2010a). Critical role of the Src homology 2 (SH2) domain of neuronal SH2B1 in the regulation of body weight and glucose homeostasis in mice. Endocrinology 151, 3643-3651.

Morris, M. K., Saez-Rodriguez, J., Sorger, P. K., and Lauffenburger, D. A. (2010b). Logic-based models for the analysis of cell signaling networks. Biochemistry 49, 3216-3224.

Morris, D. L., Cho, K. W., Zhou, Y. and Rui, L. (2009). SH2B1 enhances insulin sensitivity by both stimulating the insulin receptor and inhibiting tyrosine dephosphorylation of insulin receptor substrate proteins. Diabetes 58, 2039-2047.

Morris, M. K., Saez-Rodriguez, J., Clarke, D. C., Sorger, P. K., and Lauffenburger, D. A. (2011). Training signaling pathway maps to biochemical data with constrained fuzzy logic: quantitative analysis of liver cell responses to inflammatory stimuli. PLoS Comput. Biol. 7, e1001099. doi:10.1371/journal.pcbi.1001099

Mulligan, C., Rochford, J., Denyer, G., Stephens, R., Yeo, G., Freeman, T., Siddle, K., and O'Rahilly, S. (2002). Microarray analysis of insulin and insulin-like growth factor-1 (IGF-1) receptor signaling reveals the selective up-regulation of the mitogen heparin-binding EGF-like growth factor by IGF-1. J. Biol. Chem. 277, 42480-42487.

Myers, M. G. Jr., Mendez, R., Shi, P., Pierce, J. H., Rhoads, R., and White, M. F. (1998). The COOH-terminal tyrosine phosphorylation sites on IRS- 1 bind SHP-2 and negatively regulate insulin signaling. J. Biol. Chem. 273, 26908-26914.

Najjar, S. M. (2002). Regulation of insulin action by CEACAM1. Trends Endocrinol. Metab. 13, 240-245.

Nakae, J., Kido, Y., and Accili, D. (2001). Distinct and overlapping functions of insulin and IGF-I receptors. Endocr. Rev. 22, 818-835.

Narasimhan, S. D., Yen, K., and Tissenbaum, H. A. (2009). Converging pathways in lifespan regulation. Curr. Biol. 19, R657-R666.

Natalicchio, A., Tortosa, F., Perrini, S., Laviola, L., and Giorgino, F. (2011). p66Shc, a multifaceted protein linking Erk signalling, glucose metabolism, and oxidative stress. Arch. Physiol. Biochem. 117, 116-124.

Nelson, J. D., Leboeuf, R. C., and Bomsztyk, K. (2011). Direct recruitment of insulin receptor and ERK signaling cascade to insulin-inducible gene loci. Diabetes 60, 127-137.

$\mathrm{Ng}$, Y., Ramm, G., and James, D. E. (2010). Dissecting the mechanism of insulin resistance using a novel heterodimerization strategy to activate Akt. J. Biol. Chem. 285, 5232-5239.

Nishi, M., Werner, E. D., Oh, B. C., Frantz, J. D., Dhe-Paganon, S., Hansen, L., Lee, J., and Shoelson, S. E. (2005). Kinase activation through dimerization by human SH2-B. Mol. Cell. Biol. 25, 2607-2621.

Nishida, K., and Hirano, T. (2003). The role of Gab family scaffolding adapter proteins in the signal transduction of cytokine and growth factor receptors. Cancer Sci. 94, 1029-1033.

Noguchi, T., Matozaki, T., Inagaki, K., Tsuda, M., Fukunaga, K., Kitamura, Y., Kitamura, T., Shii, K., Yamanashi, Y., and Kasuga, M. (1999). Tyrosine phosphorylation of p62(Dok) induced by cell adhesion and insulin possible role in cell migration. EMBO J. 18, 1748-1760.

Nouaille, S., Blanquart, C., Zilberfarb, V., Boute, N., Perdereau, D. Roix, J., Burnol, A. F., and Issad, T. (2006). Interaction with Grb14 results in site-specific regulation of tyrosine phosphorylation of the insulin receptor. EMBO Rep. 7, 512-518.

O'Brien, K. B., O'Shea, J. J., and CarterSu, C. (2002). SH2-B family members differentially regulate JAK family tyrosine kinases. J. Biol. Chem. 277, 8673-8681.

O’Donovan, H. C., Kiely, P. A., and O'Connor, R. (2007). Effects of RACK1 on cell migration and IGFI signalling in cardiomyoctes are not dependent on an association with the IGF-IR. Cell. Signal. 19, 2588-2595.

Okada, S., Kao, A. W., Ceresa, B. P., Blaikie, P., Margolis, B., and Pessin, J. E. (1997). The 66-kDa Shc isoform is a negative regulator of the epidermal growth factor-stimulated mitogen-activated protein kinase pathway. J. Biol. Chem. 272, 28042-28049.

Onnockx, S., De Schutter, J., Blockmans, M., Xie, J., Jacobs, C., Vanderwinden, J. M., Erneux, C., and Pirson, I. (2008). The association between the $\mathrm{SH} 2$-containing inositol polyphosphate 5-Phosphatase 2 (SHIP2) and the adaptor protein APS has an impact on biochemical properties of both partners. J. Cell. Physiol. 214, 260-272.

Onnockx, S., Xie, J., Degraef, C., Erneux, C., and Pirson, I. (2009). Insulin increase in MAP kinase phosphorylation is shifted to early time-points by overexpressing APS, while Akt phosphorylation is not influenced. Exp. Cell Res. 315, 2479-2486. 
O'Shea, J. J., Gadina, M., and Schreiber, R. D. (2002). Cytokine signaling in 2002: new surprises in the Jak/Stat pathway. Cell 109(Suppl.), S121S131.

Ottinger, E. A., Botfield, M. C., and Shoelson, S. E. (1998). Tandem SH2 domains confer high specificity in tyrosine kinase signaling. J. Biol. Chem. 273, 729-735.

Palsgaard, J., Brown, A. E., Jensen, M., Borup, R., Walker, M., and De Meyts, P. (2009). Insulin-like growth factor I (IGF-I) is a more potent regulator of gene expression than insulin in primary human myoblasts and myotubes. Growth Horm. IGF Res. $19,168-178$

Patrussi, L., Savino, M. T., Pellegrini, M., Paccani, S. R., Migliaccio, E., Plyte, S., Lanfrancone, L., Pelicci, P. G., and Baldari, C. T. (2005). Cooperation and selectivity of the two Grb2 binding sites of p52Shc in Tcell antigen receptor signaling to Ras family GTPases and Myc-dependent survival. Oncogene 24, 2218-2228.

Peruzzi, F., Prisco, M., Dews, M., Salomoni, P., Grassilli, E., Romano, G., Calabretta, B., and Baserga, R. (1999). Multiple signaling pathways of the insulin-like growth factor 1 receptor in protection from apoptosis. Mol. Cell. Biol. 19, 7203-7215.

Pillay, T. S., Whittaker, J., Lammers, R., Ullrich, A., and Siddle, K. (1991). Multisite serine phosphorylation of the insulin and IGF-I receptors in transfected cells. FEBS Lett. 288, 206-211.

Plum, L., Belgardt, B. F., and Bruning, J. C. (2006). Central insulin action in energy and glucose homeostasis. J. Clin. Invest. 116, 1761-1766.

Podlecki, D. A., Smith, R. M., Kao, M., Tsai, P., Huecksteadt, T., Brandenburg, D., Lasher, R. S., Jarett, L., and Olefsky, J. M. (1987). Nuclear translocation of the insulin receptor. A possible mediator of insulin's long term effects. J. Biol. Chem. 262, 3362-3368.

Pollak, M. (2008). Insulin and insulinlike growth factor signalling in neoplasia. Nat. Rev. Cancer 8, 915-928.

Povsic, T. J., Kohout, T. A., and Lefkowitz, R. J. (2003). Betaarrestinl mediates insulin-like growth factor 1 (IGF-1) activation of phosphatidylinositol 3-kinase (PI3K) and anti-apoptosis. J. Biol. Chem. 278, 51334-51339.

Pruett, W., Yuan, Y., Rose, E., Batzer, A. G., Harada, N., and Skolnik, E. Y. (1995). Association between GRB2/Sos and insulin receptor substrate 1 is not sufficient for activation of extracellular signal-regulated kinases by interleukin-4: implications for Ras activation by insulin. Mol. Cell. Biol. 15, 1778-1785.

Qian, X., and Ginty, D. D. (2001). SH2$\mathrm{B}$ and APS are multimeric adapters that augment TrkA signaling. Mol. Cell. Biol. 21, 1613-1620.

Rakatzi, I., Ramrath, S., Ledwig, D., Dransfeld, O., Bartels, T., Seipke, G., and Eckel, J. (2003). A novel insulin analog with unique properties: LysB3,GluB29 insulin induces prominent activation of insulin receptor substrate 2, but marginal phosphorylation of insulin receptor substrate 1. Diabetes 52,2227-2238

Rakatzi, I., Stosik, M., Gromke, T., Siddle, K., and Eckel, J. (2006). Differential phosphorylation of IRS- 1 and IRS-2 by insulin and IGF-I receptors. Arch. Physiol. Biochem. 112, 37-47.

Ramos, F. J., Langlais, P. R., Hu, D., Dong, L. Q., and Liu, F. (2006). Grb10 mediates insulin-stimulated degradation of the insulin receptor: a mechanism of negative regulation. Am. J. Physiol. Endocrinol. Metab. 290, E1262-E1266.

Ramos, J. W. (2008). The regulation of extracellular signal-regulated kinase (ERK) in mammalian cells. Int. J. Biochem. Cell Biol. 40, 2707-2719.

Razzini, G., Ingrosso, A., Brancaccio, A., Sciacchitano, S., Esposito, D. L., and Falasca, M. (2000). Different subcellular localization and phosphoinositides binding of insulin receptor substrate protein pleckstrin homology domains. Mol. Endocrinol. 14, 823-836.

Rea, R., Gray, S., and Donnelly, R. (2005). Contrasting effects of insulin and cellular differentiation on expression of the novel insulin receptor substrate APS in skeletal muscle. Biochem. Pharmacol. 70, 1309-1311.

Ren, D., Zhou, Y., Morris, D., Li, M., Li, Z., and Rui, L. (2007). Neuronal SH2B1 is essential for controlling energy and glucose homeostasis. $J$. Clin. Invest. 117, 397-406.

Rhee, S. G., Kang, S. W., Jeong, W., Chang, T. S., Yang, K. S., and Woo, H. A. (2005). Intracellular messenger function of hydrogen peroxide and its regulation by peroxiredoxins. Curr. Opin. Cell Biol. 17, 183-189.

Riedel, H. (2004). Grb10 exceeding the boundaries of a common signaling adapter. Front. Biosci. 9, 603-618.

Riedel, H., Yousaf, N., Zhao, Y., Dai, H., Deng, Y., and Wang, J. (2000). PSM, a mediator of PDGF-BB-, IGF-I-, and insulin-stimulated mitogenesis. Oncogene 19, 39-50.

Rocchi, S., Tartare-Deckert, S., Murdaca, J., Holgado-Madruga, M.,
Wong, A. J., and Van Obberghen, E. (1998). Determination of Gabl (Grb2-associated binder-1) interaction with insulin receptor-signaling molecules. Mol. Endocrinol. 12, 914-923.

Rocchi, S., Tartare-Deckert, S., SawkaVerhelle, D., Gamha, A., and Van Obberghen, E. (1996). Interaction of SH2-containing protein tyrosine phosphatase 2 with the insulin receptor and the insulin-like growth factor-I receptor: studies of the domains involved using the yeast two-hybrid system. Endocrinology 137, 4944-4952.

Romanelli, R. J., Lebeau, A. P., Fulmer, C. G., Lazzarino, D. A., Hochberg, A., and Wood, T. L. (2007). Insulin-like growth factor type-I receptor internalization and recycling mediate the sustained phosphorylation of Akt. J. Biol. Chem. 282, 22513-22524.

Ron, D., Chen, C. H., Caldwell, J. Jamieson, L., Orr, E., and MochlyRosen, D. (1994). Cloning of an intracellular receptor for protein kinase $\mathrm{C}$ : a homolog of the beta subunit of G proteins. Proc. Natl. Acad. Sci. U.S.A. 91, 839-843.

Ross, S. H., Lindsay, Y., Safrany, S. T., Lorenzo, O., Villa, F., Toth, R., Clague, M. J., Downes, C. P., and Leslie, N. R. (2007). Differential redox regulation within the PTP superfamily. Cell. Signal. 19, 1521-1530.

Rowland, A. F., Fazakerley, D. J., and James, D. E. (2011). Mapping insulin/GLUT4 circuitry. Traffic 12, 672-681.

Sacco, A., Morcavallo, A., Pandini, G., Vigneri, R., and Belfiore, A. (2009). Differential signaling activation by insulin and insulin-like growth factors I and II upon binding to insulin receptor isoform A. Endocrinology 150, 3594-3602.

Sampson, S. R., and Cooper, D. R. (2006). Specific protein kinase C isoforms as transducers and modulators of insulin signaling. Mol. Genet. Metab. 89, 32-47.

Sarmay, G., Angyal, A., Kertesz, A., Maus, M., and Medgyesi, D. (2006). The multiple function of Grb2 associated binder (Gab) adaptor/scaffolding protein in immune cell signaling. Immunol. Lett. 104 76-82.

Sasaoka, T., Ishiki, M., Wada, T., Hori, H., Hirai, H., Haruta, T., Ishihara, H., and Kobayashi, M. (2001). Tyrosine phosphorylation-dependent and independent role of Shc in the regulation of IGF-1-induced mitogenesis and glycogen synthesis. Endocrinology 142, 5226-5235.
Sasaoka, T., and Kobayashi, M. (2000). The functional significance of Shc in insulin signaling as a substrate of the insulin receptor. Endocr. J. 47, 373-381.

Sawka-Verhelle, D., Tartare-Deckert, S., Decaux, J. F., Girard, J., and Van Obberghen, E. (2000). Stat $5 \mathrm{~B}$, activated by insulin in a Jakindependent fashion, plays a role in glucokinase gene transcription. Endocrinology 141, 1977-1988.

Saxton, T. M., Ciruna, B. G., Holmyard, D., Kulkarni, S., Harpal, K., Rossant, J., and Pawson, T. (2000). The SH2 tyrosine phosphatase shp2 is required for mammalian limb development. Nat. Genet. 24, 420-423.

Schmelzle, K., Kane, S., Gridley, S., Lienhard, G. E., and White, F. M. (2006). Temporal dynamics of tyrosine phosphorylation in insulin signaling. Diabetes 55, 2171-2179.

Schmidt, M. H., and Dikic, I. (2005). The $\mathrm{Cbl}$ interactome and its functions. Nat. Rev. Mol. Cell Biol. 6 , 907-918.

Scott, J. D., and Pawson, T. (2009). Cell signaling in space and time: where proteins come together and when they're apart. Science 326, 1220-1224.

Sehat, B., Andersson, S., Girnita, L., and Larsson, O. (2008). Identification of c-Cbl as a new ligase for insulinlike growth factor-I receptor with distinct roles from Mdm2 in receptor ubiquitination and endocytosis. Cancer Res. 68, 5669-5677.

Sehat, B., Andersson, S., Vasilcanu, R., Girnita, L., and Larsson, O. (2007). Role of ubiquitination in IGF-1 receptor signaling and degradation. PLoS ONE 2, e340. doi:10.1371/journal.pone. 0000340

Sehat, B., Tofigh, A., Lin, Y., Trocme, E., Liljedahl, U., Lagergren, J., and Larsson, O. (2010). SUMOylation mediates the nuclear translocation and signaling of the IGF-1 receptor. Sci. Signal. 3, ral0.

Sekharam, M., Nasir, A., Kaiser, H. E., and Coppola, D. (2003). Insulin-like growth factor 1 receptor activates c-SRC and modifies transformation and motility of colon cancer in vitro. Anticancer Res. 23, 1517-1524.

Shackleton, S., Hamer, I., Foti, M., Zumwald, N., Maeder, C., and Carpentier, J. L. (2002). Role of two dileucine-like motifs in insulin receptor anchoring to microvilli. $J$. Biol. Chem. 277, 43631-43637.

Shepherd, P. R., Withers, D. J., and Siddle, K. (1998). Phosphoinositide 3kinase: the key switch mechanism in insulin signalling. Biochem. J. 333, 471-490. 
Shisheva, A. (2008a). Phosphoinositides in insulin action on GLUT4 dynamics: not just PtdIns(3,4,5)P3. Am. J. Physiol. Endocrinol. Metab. 295, E536-E544.

Shisheva, A. (2008b). PIKfyve: partners, significance, debates and paradoxes. Cell Biol. Int. 32, 591-604.

Shumay, E., Song, X., Wang, H. Y., and Malbon, C. C. (2002). pp60Src mediates insulin-stimulated sequestration of the beta(2)-adrenergic receptor: insulin stimulates pp60Src phosphorylation and activation. Mol. Biol. Cell 13, 3943-3954.

Siddle, K., Urso, B., Niesler, C. A., Cope, D. L., Molina, L., Surinya, K. H., and Soos, M. A. (2001). Specificity in ligand binding and intracellular signalling by insulin and insulin-like growth factor receptors. Biochem. Soc. Trans. 29, 513-525.

Sirvent, A., Benistant, C., and Roche, S. (2008). Cytoplasmic signalling by the $\mathrm{c}$-Abl tyrosine kinase in normal and cancer cells. Biol. Cell 100, 617-631.

Skolnik, E. Y., Lee, C. H., Batzer, A., Vicentini, L. M., Zhou, M., Daly, R., Myers, M. J. Jr., Backer, J. M., Ullrich, A., White, M. F., and Schlessinger, J. (1993). The SH2/SH3 domaincontaining protein GRB2 interacts with tyrosine-phosphorylated IRS1 and Shc: implications for insulin control of ras signalling. EMBO J. 12, 1929-1936.

Slawson, C., Copeland, R. J., and Hart, G. W. (2010). O-GlcNAc signaling: a metabolic link between diabetes and cancer? Trends Biochem. Sci. 35, 547-555.

Smith, F. M., Holt, L. J., Garfield, A. S., Charalambous, M., Koumanov, F., Perry, M., Bazzani, R., Sheardown, S. A., Hegarty, B. D., Lyons, R. J., Cooney, G. J., Daly, R. J., and Ward, A. (2007). Mice with a disruption of the imprinted Grb10 gene exhibit altered body composition, glucose homeostasis, and insulin signaling during postnatal life. Mol. Cell. Biol. 27, 5871-5886.

Smith, R. M., Harada, S., and Jarett, L. (1997). Insulin internalization and other signaling pathways in the pleiotropic effects of insulin. Int. Rev. Cytol. 173, 243-280.

Soos, M. A., Field, C. E., and Siddle, K. (1993). Purified hybrid insulin/insulin-like growth factor-I receptors bind insulin-like growth factor-I, but not insulin, with high affinity. Biochem. J. 290, 419-426.

Sorensen, H., Whittaker, L., Hinrichsen, J., Groth, A., and Whittaker, J. (2004). Mapping of the insulin-like growth factor II binding site of the Type
I insulin-like growth factor receptor by alanine scanning mutagenesis. FEBS Lett. 565, 19-22.

Spence, S. L., Dey, B. R., Terry, C., Albert, P., Nissley, P., and Furlanetto, R. W. (2003). Interaction of 14-3-3 proteins with the insulin-like growth factor I receptor (IGFIR): evidence for a role of 14-3-3 proteins in IGFIR signaling. Biochem. Biophys. Res. Commun. 312, 1060-1066.

Srinivasan, D., Sims, J. T., and Plattner, R. (2008). Aggressive breast cancer cells are dependent on activated Abl kinases for proliferation, anchorageindependent growth and survival. Oncogene 27, 1095-1105.

Staubs, P. A., Reichart, D. R., Saltiel, A. R., Milarski, K. L., Maegawa, H., Berhanu, P., Olefsky, J. M., and Seely, B. L. (1994). Localization of the insulin receptor binding sites for the SH2 domain proteins $\mathrm{p} 85$, Syp, and GAP. J. Biol. Chem. 269, 27186-27192.

Stein, E. G., Ghirlando, R., and Hubbard, S. R. (2003). Structural basis for dimerization of the Grb10 Src homology 2 domain. Implications for ligand specificity. J. Biol. Chem. 278, 13257-13264.

Sturk, C., and Dumont, D. J. (2010). Tyrosine phosphorylation of Grb14 by Tie2. Cell Commun. Signal 8, 30.

Sun, H., Tu, X., Prisco, M., Wu, A., Casiburi, I., and Baserga, R. (2003). Insulin-like growth factor I receptor signaling and nuclear translocation of insulin receptor substrates 1 and 2. Mol. Endocrinol. 17, 472-486.

Sun, X. J., and Liu, F. (2009). Phosphorylation of IRS proteins Yin-Yang regulation of insulin signaling. Vitam. Horm. 80, 351-387.

Sun, X. J., Pons, S., Asano, T., Myers, M. G. Jr., Glasheen, E., and White, M. F. (1996). The Fyn tyrosine kinase binds Irs-1 and forms a distinct signaling complex during insulin stimulation. J. Biol. Chem. 271, 10583-10587.

Suzuki, M., Setsuie, R., and Wada, K. (2009). Ubiquitin carboxyl-terminal hydrolase 13 promotes insulin signaling and adipogenesis. Endocrinology 150, 5230-5239.

Takahashi, T., Fukuda, K., Pan, J., Kodama, H., Sano, M., Makino, S. Kato, T., Manabe, T., and Ogawa, S. (1999). Characterization of insulinlike growth factor-1-induced activation of the JAK/STAT pathway in rat cardiomyocytes. Circ. Res. 85, 884-891.

Takahashi, Y., Tobe, K., Kadowaki, H., Katsumata, D., Fukushima, Y., Yazaki, Y., Akanuma, Y., and Kadowaki, T. (1997). Roles of insulin receptor substrate-1 and Shc on insulin-like growth factor I receptor signaling in early passages of cultured human fibroblasts. Endocrinology 138, 741-750.

Taniguchi, C. M., Emanuelli, B., and Kahn, C. R. (2006). Critical nodes in signalling pathways: insights into insulin action. Nat. Rev. Mol. Cell Biol. 7, 85-96.

Taniguchi, C. M., Ueki, K., and Kahn, R. (2005). Complementary roles of IRS- 1 and IRS- 2 in the hepatic regulation of metabolism. J. Clin. Invest. $115,718-727$.

Tavare, J. M., and Siddle, K. (1993). Mutational analysis of insulin receptor function: consensus and controversy. Biochim. Biophys. Acta 1178 21-39.

Tavare, J. M., Zhang, B., Ellis, L., and Roth, R. A. (1991). Insulinstimulated serine and threonine phosphorylation of the human insulin receptor. An assessment of the role of serines 1305/1306 and threonine 1348 by their replacement with neutral or negatively charged amino acids. J. Biol. Chem. 266, 21804-21809.

Thien, C. B., and Langdon, W. Y. (2005). c-Cbl and Cbl-b ubiquitin ligases: substrate diversity and the negative regulation of signalling responses. Biochem. J. 391, 153-166.

Thirone, A. C., Huang, C., and Klip, A. (2006). Tissue-specific roles of IRS proteins in insulin signaling and glucose transport. Trends Endocrinol. Metab. 17, 72-78.

Thomas, D., and Bradshaw, R. A. (1997). Differential utilization of ShcA tyrosine residues and functional domains in the transduction of epidermal growth factorinduced mitogen-activated protein kinase activation in 293T cells and nerve growth factor-induced neurite outgrowth in PC12 cells. Identification of a new Grb2.Sos1 binding site. J. Biol. Chem. 272, 22293-22299.

Thorleifsson, G., Walters, G. B., Gudbjartsson, D. F., Steinthorsdottir, V., Sulem, P., Helgadottir, A., Styrkarsdottir, U., Gretarsdottir, S., Thorlacius, S., Jonsdottir, I., Jonsdottir, T., Olafsdottir, E. J., Olafsdottir, G. H., Jonsson, T., Jonsson, F., BorchJohnsen, K., Hansen, T., Andersen, G., Jorgensen, T., Lauritzen, T., Aben, K. K., Verbeek, A. L., Roeleveld, N., Kampman, E., Yanek, L. R., Becker, L. C., Tryggvadottir, L., Rafnar, T., Becker, D. M., Gulcher, J., Kiemeney, L. A., Pedersen, O., Kong, A., Thorsteinsdottir, U., and Stefansson, K. (2009). Genome-wide association yields new sequence variants at seven loci that associate with measures of obesity. Nat. Genet. 41, 18-24.

Tombes, R. M., Auer, K. L., Mikkelsen, R., Valerie, K., Wymann, M. P., Marshall, C. J., Mcmahon, M., and Dent, P. (1998). The mitogenactivated protein (MAP) kinase cascade can either stimulate or inhibit DNA synthesis in primary cultures of rat hepatocytes depending upon whether its activation is acute/phasic or chronic. Biochem. J. 330, 1451-1460.

Traverse, S., Gomez, N., Paterson, H., Marshall, C., and Cohen, P. (1992). Sustained activation of the mitogenactivated protein (MAP) kinase cascade may be required for differentiation of PC12 cells. Comparison of the effects of nerve growth factor and epidermal growth factor. Biochem. J. 288, 351-355.

Traverse, S., Seedorf, K., Paterson, H., Marshall, C. J., Cohen, P., and Ullrich, A. (1994). EGF triggers neuronal differentiation of PC12 cells that overexpress the EGF receptor. Curr. Biol. 4, 694-701.

Trinei, M., Berniakovich, I., Beltrami, E. Migliaccio, E., Fassina, A., Pelicci, P., and Giorgio, M. (2009). P66Shc signals to age. Aging (Albany NY) 1 , 503-510.

Trub, T., Choi, W. E., Wolf, G., Ottinger, E., Chen, Y., Weiss, M., and Shoelson, S. E. (1995). Specificity of the PTB domain of Shc for beta turn-forming pentapeptide motifs amino-terminal to phosphotyrosine. J. Biol. Chem. 270, 18205-18208.

Uhles, S., Moede, T., Leibiger, B., Berggren, P. O., and Leibiger, I. B. (2003). Isoform-specific insulin receptor signaling involves different plasma membrane domains. J. Cell Biol. 163, 1327-1337.

Ullrich, A., Bell, J. R., Chen, E. Y., Herrera, R., Petruzzelli, L. M., Dull, T. J., Gray, A., Coussens, L., Liao, Y. C., Tsubokawa, M., Mason, A., Seeburg, P. H., Grunfeld, C., Rosen, O. M., and Ramachandran, J. (1985). Human insulin receptor and its relationship to the tyrosine kinase family of oncogenes. Nature 313, 756-761.

Ullrich, A., Gray, A., Tam, A. W., YangFeng, T., Tsubokawa, M., Collins, C. Henzel, W., Le Bon, T., Kathuria, S., Chen, E., Jacobs, S., Francke, U., Ramachandran, J., and FujitaYamaguchi, Y. (1986). Insulin-like growth factor I receptor primary structure: comparison with insulin receptor suggests structural determinants that define functional specificity. $E M B O ~ J .5,2503-2512$. 
Urso, B., Cope, D. L., Kalloo-Hosein, H. E., Hayward, A. C., Whitehead, J. P., O'Rahilly, S., and Siddle, K. (1999). Differences in signaling properties of the cytoplasmic domains of the insulin receptor and insulin-like growth factor receptor in 3T3-L1 adipocytes. J. Biol. Chem. 274, 30864-30873.

van der Geer, P., Hunter, T., and Lindberg, R. A. (1994). Receptor proteintyrosine kinases and their signal transduction pathways. Annu. Rev. Cell Biol. 10, 251-337.

Van Obberghen, E., Baron, V., Delahaye, L., Emanuelli, B., Filippa, N., Giorgetti-Peraldi, S., Lebrun, P., Mothe-Satney, I., Peraldi, P., Rocchi, S., Sawka-Verhelle, D., TartareDeckert, S., and Giudicelli, J. (2001). Surfing the insulin signaling web. Eur. J. Clin. Invest. 31, 966-977.

Vardatsikos, G., Sahu, A., and Srivastava, A. K. (2009). The insulinlike growth factor family: molecular mechanisms, redox regulation, and clinical implications. Antioxid. Redox Signal. 11, 1165-1190.

Vecchione, A., Marchese, A., Henry, P., Rotin, D., and Morrione, A. (2003). The Grb10/Nedd4 complex regulates ligand-induced ubiquitination and stability of the insulinlike growth factor I receptor. Mol. Cell. Biol. 23, 3363-3372.

Velloso, L. A., Carvalho, C. R., Rojas, F. A., Folli, F., and Saad, M. J. (1998). Insulin signalling in heart involves insulin receptor substrates-1 and 2, activation of phosphatidylinositol 3-kinase and the JAK 2-growth related pathway. Cardiovasc. Res. 40, 96-102.

Versteyhe, S., Blanquart, C., Hampe, C., Mahmood, S., Christeff, N., De Meyts, P., Gray, S. G., and Issad, T. (2010). Insulin receptor substrates5 and -6 are poor substrates for the insulin receptor. Mol. Med. Rep. 3, 189-193.

Vinayagam, A., Stelzl, U., Foulle, R., Plassmann, S., Zenkner, M., Timm, J., Assmus, H. E., Andrade-Navarro, M. A., and Wanker, E. E. (2011). A directed protein interaction network for investigating intracellular signal transduction. Sci. Signal. 4, rs8.

Vinciguerra, M., and Foti, M. (2006). PTEN and SHIP2 phosphoinositide phosphatases as negative regulators of insulin signalling. Arch. Physiol. Biochem. 112, 89-104.

Vogt, B., Carrascosa, J. M., Ermel, B., Ullrich, A., and Haring, H. U. (1991). The two isotypes of the human insulin receptor (HIR$A$ and HIR-B) follow different internalization kinetics. Biochem.
Biophys. Res. Commun. 177, Whelan, S. A., Lane, M. D., and Hart, 1013-1018.

Voliovitch, H., Schindler, D. G., Hadari, Y. R., Taylor, S. I., Accili, D., and Zick, Y. (1995). Tyrosine phosphorylation of insulin receptor substrate-1 in vivo depends upon the presence of its pleckstrin homology region. $J$. Biol. Chem. 270, 18083-18087.

Walters, R. G., Jacquemont, S., Valsesia, A., De Smith, A. J., Martinet, D., Andersson, J., Falchi, M., Chen, F., Andrieux, J., Lobbens, S., Delobel, B., Stutzmann, F., El-Sayed Moustafa, J. S., Chevre, J. C., Lecoeur, C., Vatin, V., Bouquillon, S., Buxton, J. L., Boute, O., Holder-Espinasse, M., Cuisset, J. M., Lemaitre, M. P., Ambresin, A. E., Brioschi, A., Gaillard, M., Giusti, V., Fellmann, F., Ferrarini, A., Hadjikhani, N., Campion, D., Guilmatre, A., Goldenberg, A., Calmels, N., Mandel, J. L., Le Caignec, C., David, A., Isidor, B., Cordier, M. P., DupuisGirod, S., Labalme, A., Sanlaville, D., Beri-Dexheimer, M., Jonveaux, P., Leheup, B., Ounap, K., Bochukova, E. G., Henning, E., Keogh, J., Ellis, R. J., Macdermot, K. D., Van Haelst, M. M., Vincent-Delorme, C., Plessis, G., Touraine, R., Philippe, A., Malan, V., Mathieu-Dramard, M., Chiesa, J., Blaumeiser, B., Kooy, R. F., Caiazzo, R., Pigeyre, M., Balkau, B., Sladek, R., Bergmann, S., Mooser, V., Waterworth, D., Reymond, A., Vollenweider, P., Waeber, G., Kurg, A., Palta, P., Esko, T., Metspalu, A., Nelis, M., Elliott, P., Hartikainen, A. L., Mccarthy, M. I., Peltonen, L., Carlsson, L., Jacobson, P., Sjostrom, L., Huang, N., Hurles, M. E., O’Rahilly, S., Farooqi, I. S., Mannik, K., Jarvelin, M. R., Pattou, F., Meyre, D., Walley, A. J., Coin, L. J., Blakemore, A. I., Froguel, P., and Beckmann, J. S. (2010). A new highly penetrant form of obesity due to deletions on chromosome 16p11.2. Nature 463, 671-675.

Weiland, M., Bahr, F., Hohne, M., Schurmann, A., Ziehm, D., and Joost, H. G. (1991). The signaling potential of the receptors for insulin and insulinlike growth factor I (IGF-I) in 3T3L1 adipocytes: comparison of glucose transport activity, induction of oncogene c-fos, glucose transporter mRNA, and DNA-synthesis. J. Cell. Physiol. 149, 428-435.

Whelan, S. A., Dias, W. B., Thiruneelakantapillai, L., Lane, M. D., and Hart, G. W. (2010). Regulation of insulin receptor substrate 1 (IRS-1)/ AKT kinase-mediated insulin signaling by $O$-linked beta- $N$-acetylglucosamine in 3T3-L1 adipocytes. J. Biol. Chem. 285, 5204-5211.
G. W. (2008). Regulation of the $\mathrm{O}$-linked beta- $\mathrm{N}$-acetylglucosamine transferase by insulin signaling. $J$. Biol. Chem. 283, 21411-21417.

White, M. F. (2002). IRS proteins and the common path to diabetes. Am. J. Physiol. Endocrinol. Metab. 283, E413-E422.

Wick, M. J., Dong, L. Q., Hu, D., Langlais, P., and Liu, F. (2001). Insulin receptor-mediated p62dok tyrosine phosphorylation at residues 362 and 398 plays distinct roles for binding GTPase-activating protein and Nck and is essential for inhibiting insulin-stimulated activation of Ras and Akt. J. Biol. Chem. 276, 42843-42850.

Wilcox, A., Katsanakis, K. D., Bheda, F., and Pillay, T. S. (2004). Asb6, an adipocyte-specific ankyrin and SOCS box protein, interacts with APS to enable recruitment of elongins $\mathrm{B}$ and $\mathrm{C}$ to the insulin receptor signaling complex. J. Biol. Chem. 279, 38881-38888.

Willer, C. J., Speliotes, E. K., Loos, R. J. F., Li, S., Lindgren, C. M., Heid, I. M., Berndt, S. I., Elliott, A. L., Jackson, A. U., Lamina, C., Lettre, G., Lim, N., Lyon, H. N., Mccarroll, S. A., Papadakis, K., Qi, L., Randall, J. C., Roccasecca, R. M., Sanna, S., Scheet, P., Weedon, M. N., Wheeler, E., Zhao, J. H., Jacobs, L. C., Prokopenko, I., Soranzo, N., Tanaka, T., Timpson, N. J., Almgren, P., Bennett, A., Bergman, R. N., Bingham, S. A., Bonnycastle, L. L., Brown, M., Burtt, N. P., Chines, P., Coin, L., Collins, F. S., Connell, J. M., Cooper, C., Smith, G. D., Dennison, E. M., Deodhar, P., Elliott, P., Erdos, M. R., Estrada, K., Evans, D. M., Gianniny, L., Gieger, C., Gillson, C. J., Guiducci, C., Hackett, R., Hadley, D., Hall, A. S., Havulinna, A. S., Hebebrand, J., Hofman, A., Isomaa, B., Jacobs, K. B., Johnson, T., Jousilahti, P., Jovanovic, Z., Khaw, K. T., Kraft, P., Kuokkanen, M., Kuusisto, J., Laitinen, J., Lakatta, E. G., Luan, J., Luben, R. N., Mangino, M., Mcardle, W. L., Meitinger, T., Mulas, A., Munroe, P. B., Narisu, N., Ness, A. R., Northstone, K., O’Rahilly, S., Purmann, C., Rees, M. G., Ridderstrale, M., Ring, S. M., Rivadeneira, F., Ruokonen, A., Sandhu, M. S., Saramies, J., Scott, L. J., Scuteri, A., Silander, K., Sims, M. A., Song, K., Stephens, J., Stevens, S., Stringham, H. M., Tung, Y. C., Valle, T. T., Van Duijn, C. M., Vimaleswaran, K. S., Vollenweider, P., Waeber, G., Wallace, C., Watanabe, R. M., Waterworth, D. M., Watkins, N., Witteman, J. C., Zeggini, E., Zhai, G., Zillikens, M. C., Altshuler,
D., Caulfield, M. J., Chanock, S. J., Farooqi, I. S., Ferrucci, L., Guralnik, J. M., Hattersley, A. T., Hu, F. B., Jarvelin, M. R., Laakso, M., Mooser, V., Ong, K. K., Ouwehand, W. H., Salomaa, V., Samani, N. J., Spector, T. D., Tuomi, T., Tuomilehto, J., Uda, M., Uitterlinden, A. G., Wareham, N. J., Deloukas, P., Frayling, T. M., Groop, L. C., Hayes, R. B., Hunter, D. J., Mohlke, K. L., Peltonen, L., Schlessinger, D., Strachan, D. P., Wichmann, H. E., McCarthy, M. I., Boehnke, M., Barroso, I., Abecasis, G. R., and Hirschhorn, J. N., for the GIANT Consortium. (2009). Six new loci associated with body mass index highlight a neuronal influence on body weight regulation. Nat. Genet. 41, 25-34.

Wilson, C. M., Mitsumoto, Y., Maher, F., and Klip, A. (1995). Regulation of cell surface GLUT1, GLUT3, and GLUT4 by insulin and IGFI in L6 myotubes. FEBS Lett. 368, 19-22.

Wolf, G., Trub, T., Ottinger, E., Groninga, L., Lynch, A., White, M. F., Miyazaki, M., Lee, J., and Shoelson, S. E. (1995). PTB domains of IRS-1 and Shc have distinct but overlapping binding specificities. J. Biol. Chem. 270, 27407-27410.

Wu, A., Sciacca, L., and Baserga, R. (2003). Nuclear translocation of insulin receptor substrate- 1 by the insulin receptor in mouse embryo fibroblasts. J. Cell. Physiol. 195, 453-460.

Wu, C. J., O'Rourke, D. M., Feng, G. S., Johnson, G. R., Wang, Q., and Greene, M. I. (2001). The tyrosine phosphatase SHP-2 is required for mediating phosphatidylinositol 3-kinase/Akt activation by growth factors. Oncogene 20, 6018-6025.

Wu, J., Tseng, Y. D., Xu, C. F., Neubert, T. A., White, M. F., and Hubbard, S. R. (2008). Structural and biochemical characterization of the KRLB region in insulin receptor substrate2. Nat. Struct. Mol. Biol. 15, 251-258.

Xiao, S., Rose, D. W., Sasaoka, T., Maegawa, H., Burke, T. R. Jr., Roller, P. P., Shoelson, S. E., and Olefsky, J. M. (1994). Syp (SH-PTP2) is a positive mediator of growth factor-stimulated mitogenic signal transduction. J. Biol. Chem. 269, 21244-21248.

Yadav, A., Kalita, A., Dhillon, S., and Banerjee, K. (2005). JAK/STAT3 pathway is involved in survival of neurons in response to insulin-like growth factor and negatively regulated by suppressor of cytokine 
signaling-3. J. Biol. Chem. 280, 31830-31840.

Yamaguchi, Y., Flier, J. S., Benecke, H., Ransil, B. J., and Moller, D. E. (1993). Ligand-binding properties of the two isoforms of the human insulin receptor. Endocrinology 132, 1132-1138.

Yamaguchi, Y., Flier, J. S., Yokota, A., Benecke, H., Backer, J. M., and Moller, D. E. (1991). Functional properties of two naturally occurring isoforms of the human insulin receptor in Chinese hamster ovary cells. Endocrinology 129, 2058-2066.

Yamauchi, K., Milarski, K. L., Saltiel, A. R., and Pessin, J. E. (1995). Proteintyrosine-phosphatase SHPTP2 is a required positive effector for insulin downstream signaling. Proc. Natl. Acad. Sci. U.S.A. 92, 664-668.

Yamauchi, K., and Pessin, J. E. (1994). Insulin receptor substrate-1 (IRS1) and Shc compete for a limited pool of Grb2 in mediating insulin downstream signaling. J. Biol. Chem. 269, 31107-31114.

Yang, X., Ongusaha, P. P., Miles, P. D., Havstad, J. C., Zhang, F., So, W. V., Kudlow, J. E., Michell, R. H., Olefsky, J. M., Field, S. J., and Evans, R. M. (2008). Phosphoinositide signalling links $\mathrm{O}-\mathrm{GlcNAc}$ transferase to insulin resistance. Nature 451, 964-969.

Yenush, L., Makati, K. J., Smith-Hall, J., Ishibashi, O., Myers, M. G. Jr., and White, M. F. (1996). The pleckstrin homology domain is the principal link between the insulin receptor and IRS-1. J. Biol. Chem. 271, 24300-24306.

Youngren, J. F. (2007). Regulation of insulin receptor function. Cell. Mol. Life Sci. 64, 873-891.

Yu, Y., Yoon, S. O., Poulogiannis, G., Yang, Q., Ma, X. M., Villen, J., Kubica, N., Hoffman, G. R., Cantley, L. C., Gygi, S. P., and Blenis, J. (2011). Phosphoproteomic analysis identifies Grb10 as an mTORC1 substrate that negatively regulates insulin signaling. Science 332, 1322-1326.

Zapf, A., Hsu, D., and Olefsky, J. M. (1994). Comparison of the intracellular itineraries of insulin-like growth factor-I and insulin and their receptors in Rat-1 fibroblasts. Endocrinology 134, 2445-2452.

Zeidan, Q., and Hart, G. W. (2010). The intersections between O-GlcNAcylation and phosphorylation: implications for multiple signaling pathways. J. Cell. Sci. 123, 13-22.

Zhang, M., Deng, Y., Tandon, R., Bai, C., and Riedel, H. (2008). Essential role of PSM/SH2-B variants in insulin receptor catalytic activation and the resulting cellular responses. J. Cell. Biochem. 103, 162-181.

Zhang, M., and Riedel, H. (2009). Insulin receptor kinase-independent signaling via tyrosine phosphorylation of phosphatase PHLPP1. J. Cell. Biochem. 107, 65-75.

Zhang, W., Zong, C. S., Hermanto, U., Lopez-Bergami, P., Ronai, Z., and Wang, L. H. (2006). RACK1 recruits STAT3 specifically to insulin and insulin-like growth factor 1 receptors for activation, which is important for regulating anchorageindependent growth. Mol. Cell. Biol. 26, 413-424.

Zhou, Q. L., Park, J. G., Jiang, Z Y., Holik, J. J., Mitra, P., Semiz, S., Guilherme, A., Powelka, A. M., Tang, X., Virbasius, J., and Czech, M. P. (2004). Analysis of insulin signalling by RNAi-based gene silencing. Biochem. Soc. Trans. $32,817-821$.

Zong, C. S., Chan, J., Levy, D. E., Horvath, C., Sadowski, H. B., and Wang, L. H. (2000). Mechanism of STAT3 activation by insulin-like growth factor I receptor. J. Biol. Chem. 275, 15099-15105.
Zwang, Y., and Yarden, Y. (2009). Systems biology of growth factorinduced receptor endocytosis. Traffic 10, 349-363.

Conflict of Interest Statement: The author declares that the research was conducted in the absence of any commercial or financial relationships that could be construed as a potential conflict of interest.

Received: 15 November 2011; paper pending published: 18 December 2011; accepted: 13 February 2012; published online: 28 February 2012.

Citation: Siddle K (2012) Molecular basis of signaling specificity of insulin and IGF receptors: neglected corners and recent advances. Front. Endocrin. 3:34. doi: 10.3389/fendo.2012.00034

This article was submitted to Frontiers in Molecular and Structural Endocrinology, a specialty of Frontiers in Endocrinology. Copyright (c) 2012 Siddle. This is an open-access article distributed under the terms of the Creative Commons Attribution Non Commercial License, which permits non-commercial use, distribution, and reproduction in other forums, provided the original authors and source are credited. 